\title{
Nutritional influences on some major enteric bacterial diseases of pigs
}

\author{
John R. Pluske*, David W. Pethick, Deborah E. Hopwood and \\ David J. Hampson \\ Division of Veterinary and Biomedical Sciences, Murdoch University, Murdoch, \\ WA 6150, Australia
}

There are several enteric bacterial diseases and conditions of pigs that require control to prevent overt disease, to reduce morbidity and mortality, and to improve the efficiency of production. Traditionally, veterinarians, feed manufacturers and producers have relied upon antibiotics and minerals (for example, $\mathrm{ZnO}, \mathrm{CuSO}_{4}$ ) in diets for a large part of this control. However, recent trends, particularly in Europe, are to reduce antimicrobial use and seek alternative or replacement strategies for controlling enteric bacterial diseases. The majority of these strategies rely on 'nutrition', taken in its broadest sense, to reduce the susceptibility of pigs to these diseases. Evidence to date suggests that specific dietary interventions, for example feeding very highly-digestible diets based on cooked white rice, can reduce the proliferation of a number of specific enteric bacterial infections, such as post-weaning colibacillosis. No simple and universal way to reduce susceptibility to pathogens in the gastrointestinal tract has been identified, and the underlying basis for many of the reported positive effects of 'nutrition' on controlling enteric infections lacks robust, scientific understanding. This makes it difficult to recommend dietary guidelines to prevent or reduce enteric bacterial diseases. Furthermore, some diseases, such as porcine intestinal spirochaetosis caused by Brachyspira pilosicoli, are sometimes associated with other pathogens (co-infections). In such cases, each pathogen might have different nutrient requirements, ecological niches and patterns of metabolism for which a variety of dietary interventions are needed to ameliorate the disease. Greater understanding of how 'nutrition' influences gut epithelial biology and immunobiology, and their interactions with both commensal and pathogenic bacteria, holds promise as a means of tackling enteric disease without antimicrobial agents. In addition, it is important to consider the overall system (i.e. management, housing, welfare) of pig production in the context of controlling enteric bacterial diseases.

\section{Disease: Bacteria: Gastrointestinal tract: Pigs}

\footnotetext{
Abbreviations: CMC, carboxymethylcellulose; CP, crude protein; FLF, fermented liquid feed; NDO, non-digestible oligosaccharides; PIS, porcine intestinal spirochaetosis; PPE, porcine proliferative enteropathies; ppm, parts per million; PWC, post-weaning colibacillosis; RS, resistant starch; VFA, volatile fatty acid; SD, swine dysentery; ST, heat-stable toxin.

*Corresponding author: Dr J. R. Pluske, fax + 6189360 2487, email jpluske@murdoch.edu.au
} 


\section{Introduction}

A variety of commensal and pathogenic bacterial species colonise the gastrointestinal tract of the pig. The pathogenic bacteria can cause clinical disease, morbidity and mortality, and are a major source of economic loss to the pig industry worldwide. A number of distinct genera and species of bacteria are involved, and each of these pathogens tends to inhabit a different region of the gastrointestinal tract and is generally associated with a different age or class of pig. For example, post-weaning colibacillosis (PWC) caused by Escherichia coli specifically affects the small intestine in the first 3-10 d after weaning. The major form of control of these enteric infections is antimicrobials, which are provided to treat overt disease, to provide prophylaxis in situations where a disease (or diseases) is (are) liable to occur, and to improve growth rates in the absence of disease (the 'growth-promoting' effect of antibiotics) (Hampson et al. 2001).

In some countries though, particularly in Europe, there have been widespread bans (both legislative and voluntary) placed on the use of antimicrobials in pig diets for growth promotion. This is largely because of rising fears regarding the implications for both animal and human health (i.e. food safety) of continued use of antimicrobials in the intensive livestock industries, although other influences such as the establishment and/or protection of export markets for pork also play a role. The prolonged use of antimicrobials most likely selects for the survival of resistant bacterial species or strains, and genes encoding this resistance can be transferred to other formerly susceptible bacteria. A number of bacterial pathogens of pigs are showing resistance to a range of antimicrobial drugs (Barton, 1999). Not only is this reducing the number of antimicrobials available to the industry to control bacterial infections, but this resistance also poses risks to human health. For example, the transfer of resistant zoonotic pathogens such as Salmonella typhimurium and Campylobacter jejuni from pigs to man has been reported, and the direct or indirect transfer of resistance genes from the porcine gastrointestinal microflora to human bacterial strains also poses considerable risks (Barton, 2000; Hampson et al. 2001). Concerns about these issues are leading to reduced availability of antimicrobial agents for use in the pig industry. Consequently, it is important to develop means both of controlling bacterial infections and promoting growth in pigs without recourse to the use of antimicrobials and certain minerals, such as $\mathrm{ZnO}$ and $\mathrm{CuSO}_{4}$. In this regard, 'nutrition', in its broadest sense, has attracted enormous interest as a means of ameliorating enteric infections in pigs, and the search for antimicrobial alternatives or replacements will continue as pressure for the complete ban of growth-promoting antimicrobials in the pig industry continues to mount.

The purpose of the present review is to assimilate past and current knowledge pertaining to the use of nutrition, in its broadest sense, and its roles in causing and modulating major enteric bacterial diseases in pigs. The review will first describe the ecology of the gastrointestinal tract in relation to the genera and species present and their interactions with the host. This is followed by a discussion of the major enteric diseases in pigs that cause production and economic losses, and how the use of nutrition is involved in both the aetiology of the disease and in its modulation. Although important associations between gut immune function and disease are recognised, the gut-associated lymphoid tissue and its development will not specifically be reviewed here. The reader is directed towards several excellent recent reviews in this area by Kelly et al. (1994), Deplancke \& Gaskins (2001), Gaskins (2001), Kelly \& King (2001) and Stokes et al. (2001).

\section{The ecology of the gastrointestinal tract}

\section{What comprises the normal microflora?}

The porcine intestinal microflora is established within $48 \mathrm{~h}$ after birth via ingestion of maternal faeces, and involves complex successional changes until dense, stable populations colonise the 
gastrointestinal tract (Mackie et al. 1999). The microbiota is characterised by its high population density, extensive diversity, and complexity of interactions throughout the gastrointestinal tract. A distinction between indigenous (autochthonous) and non-indigenous (allochthonous) bacteria is required for an ecological understanding of colonisation, succession and mechanisms of host interactions. Autochthonous (indigenous) bacteria are those that have co-evolved with the host and colonise all habitats and niches in the gastrointestinal tract, whereas allochthonous (non-indigenous) bacteria may pass through specific microhabitats, being derived from food, water or another gut habitat, and do not colonise the tract (Dubos et al. 1965). Colonisation describes the process by which a population of bacteria in the gastrointestinal tract becomes stable in size over time without the need for periodic reintroduction (Gaskins, 2001). These bacteria colonise at a rate that equals or exceeds their rate of washout or elimination from an intestinal habitat. Pathogens can be autochthonous or allochthonous, and generally cause disease when the gut ecosystem is disturbed in some manner.

The stomach and proximal small intestine (duodenum) contain relatively low numbers of bacteria $\left(10^{3}-10^{5}\right.$ bacteria/g or $\mathrm{ml}$ of contents) due to low $\mathrm{pH}$ and/or rapid digesta flow. Whilst the piglet is still suckling, the dominant bacteria within the stomach and small intestine tend to be Lactobacillus spp. and Streptococcus spp. (Jensen, 1998). In the proximal small intestine, digesta flow rate and the rate of bacterial washout exceeds the maximal growth rates of most bacterial species, and the bacteria that are present typically adhere to the mucus or epithelial cell surface (Gaskins, 2001). In contrast, the distal small intestine harbours a more diverse and numerically greater $\left(10^{8} \mathrm{bacteria} / \mathrm{g}\right.$ or $\mathrm{ml}$ of contents $)$ population of bacteria. The large intestine is the major site of microbial colonisation because of the high residence time of the digesta. The luminal contents of the colon support in excess of 400 different bacterial species with numbers as high as $10^{10}$ and $10^{11}$ culturable bacteria/g (wet weight) of digesta (King \& Kelly, 2001). Characterisation of the intestinal microbiota has been conducted using anaerobe culturing techniques, and numerous studies show that the major bacterial groups isolated from the pig intestine are Streptococcus, Lactobacillus, Prevotella, Selenomona, Mitsuokella, Megasphera, Clostridia, Eubacteria, Bacteroides, Fusobacteria, Acidodaminococci, and the Enterobacteria (Salanitro et al. 1977; Allison et al. 1979; Russell, 1979; Robinson et al. 1981; Moore et al. 1987; Jensen, 2001) (Table 1). The hindgut flora is considered both diverse and stable, with the many species and strains appearing to coexist without one or few ever becoming dominant. Further information pertaining to the composition of the microbiota can be found in reviews by Stewart (1997), Mackie et al. (1999), Gaskins (2001), Jensen (2001) and Leser et al. (2002).

In addition to a proximal to distal gradient in bacterial numbers in the gastrointestinal tract, Gaskins (2001) described radial distributions of microbes within each segment of the gut. The four microhabitats for the commensal flora include: the intestinal lumen; the unstirred mucus layer, or layer that covers the mucosal epithelium; the deep mucus layer found in the crypts; the surface of the intestinal epithelial cells. The diversity of the hindgut microflora and that of the distal region of the small intestine reflects in part the types of nutrient substrates found in these regions. The diversity of bacterial populations within a particular ecosystem is directly related to the number and composition of limiting nutrients, since each limiting nutrient will support the one bacterial species or strain that is most efficient in utilising it (Gaskins, 2001). Moreover, the stability of these bacterial populations will also be influenced by the inhibitory actions of a number of compounds such as volatile fatty acids, $\mathrm{H}_{2} \mathrm{~S}$, deconjugated bile salts, $\mathrm{NH}_{3}$ and bacteriocins (Gaskins, 2001). In this regard, it is likely that certain nutrients and their associated physicochemical effects play a major role in maintaining the balance of the microflora in these parts of the gastrointestinal tract, and subsequently in determining whether a pathogenic bacteria proliferates to cause overt expression of disease. 
Table 1. The predominant bacteria cultivated from the small and large intestines of the pig (total isolates 1679) (from Jensen, 2001)

\begin{tabular}{|c|c|c|c|c|c|}
\hline \multirow[b]{2}{*}{ Isolate number } & \multicolumn{4}{|c|}{ Proportion of isolates (\%) } & \multirow[b]{2}{*}{ Similarity to known bacterial species } \\
\hline & Total & $\mathrm{SI}^{*}$ & Caecum* & ${ }^{*}$ Colon* & \\
\hline 1. Escherichia coli & $22 \cdot 0$ & $49 \cdot 0$ & $9 \cdot 6$ & $5 \cdot 5$ & E. coli $(99.8 \%)$ \\
\hline 2. Streptococcus alactolyticus & $13 \cdot 5$ & $18 \cdot 2$ & $10 \cdot 7$ & 8.4 & S. alactolyticus \\
\hline 3. Prevotella sp. 1 & $10 \cdot 0$ & 0.0 & $17 \cdot 0$ & $1 \cdot 0$ & UB adhesin $94(98.1 \%) \dagger$ \\
\hline 4. Streptococcus hyointestinalis & $9 \cdot 5$ & $11 \cdot 8$ & $8 \cdot 1$ & $6 \cdot 3$ & S. hyointestinalis \\
\hline 5. Prevotella sp. 1a & 2.9 & 0.0 & $6 \cdot 3$ & $4 \cdot 8$ & P. oulora $(92.4 \%) \dagger$ \\
\hline 6. Lactobacillus acidophilus and jonsonii & nii $2 \cdot 2$ & 0.0 & $3 \cdot 2$ & $3 \cdot 6$ & L. jonsonii (99.7\%) \\
\hline 7. Lactobacillus sp. 2 & $2 \cdot 0$ & 0.3 & 1.5 & $2 \cdot 2$ & L. vitulinus $(93.9 \%) \dagger$ \\
\hline 8. Selenomonas sp. 1 & 1.9 & 0.0 & $2 \cdot 3$ & $3 \cdot 6$ & S. ruminantum $(94.7 \%) \dagger$ \\
\hline 9. Mitsuokella sp. & 1.7 & 0.7 & 1.9 & $2 \cdot 7$ & M. multiacidicus ( $97.8 \%)$ \\
\hline 10. Megasphera sp. & $1 \cdot 7$ & 0.0 & $1 \cdot 3$ & $3 \cdot 9$ & M. elsdenii (93.7\%)† \\
\hline 11. Acidaminococcus fermentans & 1.5 & 0.3 & $4 \cdot 2$ & 1.5 & A. fermentans $(99.4 \%)$ \\
\hline 12. Clostridium perfringens & 1.5 & $2 \cdot 7$ & $1 . \overline{5}$ & 0.4 & C. perfringens $(99.7 \%)$ \\
\hline 13. Eubacterium sp. & $1 \cdot 1$ & 0.0 & $1 \cdot 3$ & 1.4 & Butyrate-producing bacteria $(96.6 \%) \dagger$ \\
\hline 14. Prevotella sp. 13 & $1 \cdot 1$ & 0.0 & 0.0 & 1.3 & Not known $(<97 \%) \dagger$ \\
\hline 15. Bacteroides sp. 1 & $1 \cdot 0$ & $0 \cdot 2$ & $2 \cdot 7$ & 0.0 & B. vulgatus $(99.5 \%)$ \\
\hline 16. Megasphera elsdenii & $1 \cdot 0$ & 0.0 & 2.5 & 0.4 & Did not survive freezing \\
\hline 17. Fusobacterium mortiferum & 1.0 & 2.9 & 0.0 & 0.0 & F. mortiferum (99.9\%) \\
\hline 18. Eubacterium sp. B & 0.4 & 0.0 & $1 \cdot 0$ & 0.9 & UB adhesin $420(95.6 \%) \dagger$ \\
\hline
\end{tabular}

SI, small intestine; UB, uncultured bacteria.

* In the small intestine there were 579 isolates, in the caecum 529 isolates and in the colon 571 isolates recovered. Rows and columns do not add up to $100 \%$ because here is shown only the predominant isolates that have been identified; there are $>600$ isolates at current estimations, hence the numbers do not equal $100 \%$.

† Isolates could not be assigned to any known species.

\section{Current studies in microbial ecology in the pig}

Concerns associated with the loss of growth-promoting antibiotics and minerals such as $\mathrm{ZnO}$ and $\mathrm{CuSO}_{4}$ in the pig industry have caused renewed interest in studying the microbial ecology of the gastrointestinal tract. Not only has this area received little scientific attention in the pig, but it has also raised many questions concerning the composition, structure and stability of ecosystems in the gut as well as the activity and function of individual inhabitants. Increased understanding of these associations is pivotal to determining both the efficacy of antimicrobial 'alternatives' or 'replacements', and developing new methods to control enteric diseases. Nevertheless, current knowledge of microbial diversity and ecology is based largely on anaerobic culture techniques that, as stated by Gaskins (2001), are limited by three major factors: culturing can only be performed on those organisms for which nutritional and growth requirements are known; there is a lack of a phylogenetically based classification scheme; there is unavoidable bias introduced by culture-based enumeration and characterisation techniques because of different survival rates in vitro.

Modern molecular techniques based on, for example, comparative sequence analysis of small subunit ribosomal RNA (16S rRNA) molecules, can be used to provide molecular characterisation (Simpson et al. 1999; Tannock, 1999), while at the same time providing a classification system that predicts natural evolutionary relationships (Pace, 1997). A recent study of microbial diversity in the mucosal layer of the pig colon with molecular analysis compared with culture-based methods highlights the problems mentioned earlier. Pryde et al. (1999) demonstrated that Streptococci spp. and Lactobacilli spp. comprised the majority of isolates recovered (54\%) from the colon wall by culturing; however these groups accounted for only 
$33 \%$ of the sequence variation for the same sample from random cloning. In addition, $59 \%$ of randomly cloned sequences showed less than $95 \%$ similarity to database entries or sequences from cultivated organisms. Data presented in Table 1 by Jensen (2001) similarly demonstrate the shortcomings of traditional culturing techniques, since numerous bacterial species present in the intestines belong to unknown species. As suggested by Jensen (2001), despite the majority of the larger bacterial populations being represented using culture techniques, it is likely that small populations performing key ecological functions may escape detection.

There is a dearth of studies investigating the bacterial ecology of the pig's gastrointestinal tract, especially using molecular techniques. Simpson et al. (1999) used denaturant gradient gel electrophoresis to measure changes in bacterial populations in the gastrointestinal tract of the pig between $18 \mathrm{~d}$ and 6 months of age. These workers detected differences in populations between different gut compartments and specific locations within each compartment. Similarly, Simpson et al. (2000) studied the diversity and stability of the faecal bacterial microbiota in weanling pigs after introduction of an exogenous Lactobacillus reuteri strain (MM53). The use of such techniques, in which individual bacterial species can be identified, is a potentially powerful tool for monitoring changes in the microbiota of individual pigs in relation to nutritional changes and disease. In this regard, Leser et al. (2002) have recently compiled a library of 4270 cloned 16S rDNA sequences representing 375 phylotypes from the ileum, caecum or the colon of pigs aged 12-18 weeks. The design of specific oligonucleotide probes to characterise the phylotypes will facilitate the analysis of many samples to characterise the responses of the intestinal bacterial community to interventions such as antibiotic replacements, probiotics, diets and so on.

\section{Interactions between the luminal bacteria and the gut epithelium}

In conjunction with the renewed interest in identifying and quantifying the microbial ecology of the pig's gastrointestinal tract, a resurgence of interest has occurred in examining the mechanisms of action and extent of 'cross talk' between the enteric bacteria and the host (for a recent review, see King \& Kelly, 2001). The chemistry and distribution of bacterial binding sites on gut mucosal surfaces play important roles in determining host and tissue susceptibility and in triggering host responses, especially in young animals (Kelly \& King, 2001). Individual mucin carbohydrates have the capacity either to repel or bind to microbial surface adhesins. Enteric bacterial strains that cause diarrhoea, for example, are generally classified according to their lectins (fimbria), which constitute proteinaceous appendages that protrude from the bacterial surface and recognise sugar moieties of glycoproteins and/or glycolipids on epithelial surfaces. The synthesis of these appendages (pili) and the production of enterotoxins are key virulence factors that enable enteric pathogens to colonise the intestines (Kelly \& King, 2001). Some evidence suggests that dietary proteolytic treatment of the glycoprotein receptors can prevent attachment of enterotoxigenic E. coli. For example, Mynott et al. (1996) and Chandler \& Mynott (1998) reported that feeding bromelain, a proteolytic extract from pineapple stems, significantly reduced K88 (+) attachment in the small intestine commensurate with decreased diarrhoea and improved weight gain in piglets.

Protection of the epithelium against the microbes lies in the capacity of mucin carbohydrates, particularly in the small intestine, to either repel or bind microbial adhesins (Belley $e t$ al. 1999). The ability to bind to mucin carbohydrates enables some bacterial groups, both commensal and pathogenic, to colonise the mucus layer. Gaskins (2001) commented that bacteria living in the mucus layer prevent the attachment of pathogenic microbes by occupying avail- 
able binding sites, although further evidence in vivo to support this claim is required. This is likely to be an active area of future research as new techniques are developed to examine the mucus layer without disrupting its integrity.

The nature of the diet, the microbial flora, and interactions between them influence the composition and functional characteristics of intestinal mucins (Sharma et al. 1997). It is likely that many enteric bacteria produce mucolytic or glycosidic enzymes that alter the chemical nature of the mucins, and an ability to degrade mucus has been documented in both commensal bacteria and pathogens (for example, see Deplancke \& Gaskins, 2001; Kelly \& King, 2001). The process of mucolysis (Deplancke \& Gaskins, 2001; Gaskins, 2001) would compromise epithelial barrier function, leading to possible bacterial translocation into the lamina propria and subsequent recruitment of inflammatory cells. This can be perceived as being a logical defensive response by the host, but this response uses energy that would otherwise be directed towards carcass gain and may also predispose to disease. A recent study showed that inclusion of galactose in the diet of weanling pigs modified the mucin (glycoprotein) composition compared with a control diet (Pestova et al. 2000), leading these authors to surmise that this dietary change might have limited the microbial degradation of mucins.

The mucus-secreting goblet cells play a crucial role in intestinal homeostasis, especially with regard to how enteric pathogens cause disease and what factors (for example, dietary, environmental) trigger these events. Changes in both the number of goblet cells and the chemical composition of the mucus layer occur under conditions of intestinal 'insults', such as weaning (Dunsford et al. 1991), dietary change (Brunsgaard, 1998), and total parenteral nutrition (Ganessunker et al. 1999). For example, Ganessunker et al. (1999) compared goblet cell and immune-related parameters in neonatal piglets fed a milk replacer intravenously via total parenteral nutrition with those fed the same diet enterally. Total goblet cell numbers in the jejunum and ileum and sulfomucin-positive goblet cells within ileal villi were increased in total parenteral nutrition-fed pigs $v$. enterally-fed pigs. Furthermore, goblet cell and mucin subtype alterations were correlated to local expansion of T-lymphocyte populations.

At present the taxonomy and distribution of bacterial groups, both commensal and pathogenic, which preferentially reside within the intestinal mucus layer must be better defined to ascertain the role of 'normal' gut bacteria in mucogenesis and mucolysis. It is generally thought that a bacterial consortium comprising several genera provide the necessary enzymes for mucolysis and perform mucin degradation in vivo. Deplancke \& Gaskins (2001) commented that microbial populations residing in mucus are poorly (if at all) characterised for the pig. As goblet cells are a key component of epithelial defence, then a greater understanding of mechanisms regulating mucin production and degradation by bacteria is necessary.

\section{Major enteric bacterial diseases of the pig}

In the future, increasing attention will be directed towards finding practical and cost-effective solutions to replace growth-promoting antimicrobials in diets for pigs. One solution is to find dietary means of ameliorating intestinal diseases. Some of these are already well established in the pig industry, for example the routine inclusion of pharmacological levels of $\mathrm{ZnO}$ and/or $\mathrm{CuSO}_{4}$ in diets. The following discussion reviews some of the major enteric bacterial diseases of pigs in relation to aspects concerning nutrition. It will attempt to identify areas and opportunities whereby nutrition may predispose pigs to enteric disease, and can be used prophylactically or therapeutically to ameliorate disease, in the absence of antimicrobial agents. 


\section{Post-weaning colibacillosis}

Pathogenesis of post-weaning colibacillosis. PWC is a disease of the small intestine. Although digesta flows relatively quickly through the small intestine, the pathogenic E. coli that proliferate in the condition possess fimbriae, or pili, that attach to the enterocytes lining the small intestinal villi or to the mucus covering the villi. Attachment prevents the bacteria from being flushed through to the large intestine. After colonising the small intestine, enterotoxigenic $E$. coli provoke hypersecretory diarrhoea through the release of specific enterotoxins. Secretion of chloride ions, sodium ions, bicarbonate ions, and water into the lumen is induced by the actions of a heat-labile toxin binding irreversibly to the mucosal cells and activating the adenyl cyclase-cyclic AMP system (Argenzio, 1992). A second heat-stable toxin (ST), with subtypes STa and STb, inhibits the absorption of sodium and chloride ions from the lumen into the epithelial cell via the guanyl cyclase-cyclic GMP system.

PWC is a major cause of mortality and morbidity worldwide. Immunity to one strain of pathogenic $E$. coli does not necessarily protect from others, and successive strains can pass through herds. Colonisation of the small intestine and diarrhoea usually last between 4 and $14 \mathrm{~d}$, with the strains being spread between animals primarily by the faecal-oral route, and also by aerosols (Bertschinger, 1999). Research has shown that most E. coli associated with PWC are enterotoxin-producing, $\beta$-haemolytic strains. The presence of particular serotypes has also been correlated with haemolytic E. coli causing clinical disease, in particular types O8, O138, O139, O141, O147, O149, and O157 (Hampson, 1994). Numerous reviews of post-weaning $E$. coli diarrhoea (or PWC) have been presented previously (Hampson, 1987, 1994; Bertschinger, 1999). It is common for haemolytic E. coli to appear in the faeces of pigs in increased numbers in the first week after weaning in both healthy and diarrhoeic pigs, although the numbers of E. coli in diarrhoeic pigs is higher (Kenworthy \& Crabb, 1963; Hampson et al. 1985). Pigs displaying PWC harbour massive numbers of haemolytic E. coli in the jejunum, whilst there is minimal change in numbers of other bacteria (Smith \& Jones, 1963).

Predisposing factors for post-weaning colibacillosis. Despite haemolytic enterotoxigenic $E$. coli being identified as the primary infectious agent in this disease, there is abundant evidence to suggest that other factors are necessary for PWC to occur (for example, see Madec et al. 1998, 2000; Jones et al. 2001). In the small intestine, E. coli fimbriae attach to glycoprotein receptors expressed in the brush border of cells lining the intestinal villi. The most common fimbriae associated with $E$. coli causing PWC is K88, renamed as F4. The receptor for F4 disappears a few weeks after weaning, offering only a brief window of opportunity for this pathogen to attach and proliferate. Some pigs do not possess the receptors for the E. coli, and some have receptors that are only weakly adhesive (Hampson, 1994).

The act of weaning is an essential precipitating factor for PWC, regardless of the age at weaning. All of the factors involved with weaning create an environment suitable for the proliferation of $E$. coli in the small intestine. Slower gut transit time and gut stasis immediately after weaning allow bacteria the opportunity to attach and time to multiply. Numerous studies (for a review, see Hampson, 1987) suggest that the form of the feed (for example, liquid $v$. dry) influences a pig's susceptibility to PWC, with a liquid feed fed at regular intervals after weaning being beneficial in reducing diarrhoea (Lecce et al. 1983). Consequently, it has been reported that restricting the amount of feed given to pigs reduces the incidence of PWC (for example, Rantzer et al. 1996), presumably because undigested food particles in the lumen of the small intestine supply less substrate for bacterial growth. In contrast, Madec et al. (1998) reported 
that low feed intake $(<1000 \mathrm{~g})$ in the first week after weaning placed piglets at a greater risk of PWC than intake in excess of this amount. In addition, the change from sows' milk to solid feed results in the loss of any passive protection provided by the milk.

An inability of piglets to adequately thermoregulate, combined with sub-standard weaning accommodation, may result in cold stress. This alters intestinal motility and is thought to be an important factor in the pathogenesis of PWC (Wathes et al. 1989). Social stresses from mixing, fighting and crowding trigger cortisol release, most likely increasing transit time (via the sympathetic nervous system) and depressing the immune response to bacterial infection. Moving to a new pen environment causes increased antigenic exposure to microbes residing in fresh or dry faecal matter. The presence of other pathogens such as rotavirus in the environment increases the likelihood and severity of disease occurring (Lecce et al. 1983), and poorer hygiene will result in a greater antigenic load delivered to the small intestine because of faecal-oral cycling (Madec et al. 1998).

Influence of carbohydrate ('fibre') sources on post-weaning colibacillosis. Numerous reports dating back to the 1960s and 1970s showed that addition of insoluble fibre sources such as the husks from cereals could reduce the excretion of haemolytic E. coli and the incidence of PWC. For example, Smith \& Halls (1968) found that barley hulls fed ad libitum, but not pearl-barley meal, prevented disease in weaner pigs inoculated with E. coli. Those fed barley meal remained susceptible to PWC. The barley fibre used in this trial was the outer hull of barley, collected in the making of pearled barley. Barley hulls contain a considerable amount of insoluble NSP and lower levels of soluble NSP (Bach Knudsen, 1997). Barley meal, on the other hand, would have a higher proportion of soluble NSP. Diets used in trials by Bertschinger et al. $(1978,1979)$ that were associated with reduced $E$. coli proliferation and diarrhoea were high in crude fibre $(10-17 \%)$ and low in nutrients, particularly crude protein $(\mathrm{CP})$.

Relatively little subsequent research has been conducted in this area, although reports of 'complex-' $v$. 'simple-'density diets (for example, Ball \& Aherne, 1982) continued to show the effects of diet on diarrhoea after weaning. However, concerns related to the use of antimicrobials in diets after weaning has caused a sharp refocus on alternative control strategies. Research on PWC at Murdoch University has examined interrelationships between different sources of NSP and proliferation of E. coli in weaner pigs. Increased proliferation of pathogenic $E$. coli in both the small and large intestines has been seen with addition of either guar gum (McDonald et al. 1999) or pearl barley (McDonald et al. 2001b) to the diet of $21 \mathrm{~d}$ old weaner pigs. For example, McDonald et al. (2001b) assessed the effect of adding a soluble NSP source (pearl barley) to a cooked white rice-based diet on the performance, gastrointestinal physiology and intestinal proliferation of enterotoxigenic $E$. coli in weaned pigs experimentally inoculated with E. coli O8; K87; K88. Pigs were infected at 48, 72 and $96 \mathrm{~h}$ after weaning, and were allowed ad libitum access to their feed. Pigs were euthanased 7-9 d after weaning. Pigs fed the rice-based diet grew faster, had a greater empty body-weight gain, and had a reduced largeintestinal weight (expressed as a proportion of empty body weight) than pigs fed the rice-based diet supplemented with pearl barley (Table 2). Lower concentrations of volatile fatty acids and a lower $\mathrm{pH}$ of digesta in the large intestine indicated greater fermentative activity in pigs fed the pearl barley-based diet. Pigs offered the rice-based diet showed a smaller reduction in empty body-weight gain associated with $E$. coli infection, and showed significantly reduced numbers of haemolytic $E$. coli in the jejunum and the colon than their counterparts fed the diet containing cooked white rice plus pearl barley (Table 2).

The addition of pearl barley to the rice-based diet altered the physicochemical properties in 
Table 2. Performance, large-intestinal weights, volatile fatty acid (VFA) levels and ileal digesta viscosity in non-infected and infected pigs fed either a rice-based diet or one containing pearl barley (from McDonald et al. 2001b)

\begin{tabular}{|c|c|c|c|c|c|c|c|}
\hline & \multicolumn{2}{|c|}{ Non-infected pigs } & \multicolumn{2}{|c|}{ Infected pigs } & \multirow[b]{2}{*}{ SEM } & \multicolumn{2}{|c|}{$P$ value } \\
\hline & Rice† & Barleył & Rice† & Barley & & Diet & Disease \\
\hline Carcass gain $(g / d)$ & 74 & 26 & -28 & -56 & $36 \cdot 3$ & * & $\star \star * *$ \\
\hline Large intestine ( $\%$ live weight) & $2 \cdot 7$ & $3 \cdot 8$ & $2 \cdot 6$ & $3 \cdot 2$ & 0.62 & ** & NS \\
\hline Distal colon VFA (mM) & 84 & 114 & 60 & 78 & $20 \cdot 4$ & $\star \star *$ & ** \\
\hline Distal colon pH & $6 \cdot 8$ & $6 \cdot 1$ & $6 \cdot 8$ & 6.5 & 0.37 & ** & NS \\
\hline Escherichia coli in jejunum§ & 0 & 0 & 0.9 & $4 \cdot 2$ & 2.44 & * & \\
\hline E. coli in colon§ & 0 & 0 & $3 \cdot 2$ & $6 \cdot 2$ & 1.89 & ** & \\
\hline Viscosity in ileum (cP) & $2 \cdot 1$ & $2 \cdot 8$ & $1 \cdot 6$ & $2 \cdot 3$ & $1 \cdot 13$ & * & * \\
\hline
\end{tabular}

${ }^{*} P<0.05,{ }^{* *} P<0.01,{ }^{* *} P<0.001$.

† Rice-based diet (g/kg diet): cooked white rice, 702; dietary soluble NSP, 4; animal protein sources, 197.

‡ Pearl barley-based diet (g/kg diet): pearl barley, 500; dietary soluble NSP, 25; rice, 275; animal protein sources, 200.

$\S$ Expressed as $\log _{10}$ colony-forming units of haemolytic E. coli/g mucosal scraping.

the intestines, increased the viscosity, and altered the site of microbial fermentation. The energy expended in adapting the intestinal tract for digestion of NSP caused a depression in carcass growth, and this was exacerbated by PWC. These data suggest that the presence of soluble NSP in weaner diets is detrimental for piglet growth and stimulates proliferation of $E$. coli in the small intestine. It also indicates that there are benefits in feeding a highly-digestible rice-based diet to weaners, although it is not at present known what mechanism(s) promote this protection. Besides cooked rice reducing E. coli numbers, work by Mathews et al. (1999) suggests that components in boiled rice also inhibit electrolyte secretions in the small intestine, and hence reduce the magnitude of secretory diarrhoea. Further understanding is needed, because highly-digestible rice-based diets may prove to be a viable alternative to the use of growth-promoting antimicrobials currently used in the control of diarrhoea after weaning.

The two types of soluble NSP used by McDonald et al. $(1999,2001 b)$ were highly fermentable and viscous in nature, which raises the question as to what extent fermentability, viscosity or combinations of both are likely to influence the small-intestinal microbiota. To investigate further the potential detrimental effects of increased intestinal viscosity in weaner pigs on proliferation of enterotoxigenic haemolytic E. coli, McDonald et al. (2001a) fed experimental diets supplemented with two sources of carboxymethylcellulose (CMC) to 21-d old weaned pigs for $10 \mathrm{~d}$. CMC is a water-soluble synthetic viscous polysaccharide resistant to microbial fermentation. The pigs were then euthanased and the effects of two types of CMC, either low-viscosity (50-200 cP in vitro) or high-viscosity (400-800 cP in vitro), on gastrointestinal development, growth performance, faecal DM and proliferation of haemolytic E. coli were monitored.

Dietary CMC increased the viscosity along the entire lumen of the small intestine and in the caecum, and resulted in increased intestinal weights. Pigs fed the rice-based diet remained healthy, whereas those fed either low- or high-viscosity CMC developed diarrhoea within $7 \mathrm{~d}$ of weaning, and this continued until they were euthanased on day 10. Pigs fed the low- or highviscosity CMC diets shed more haemolytic E. coli $(\mathrm{O} 141$; K88) daily than pigs fed the riceonly-based diet (Table 3).

The presence of CMC might provide a favourable luminal environment for the establishment and growth of bacteria, especially E. coli. This bacterium possesses pili that allow it to 
Table 3. The effect of dietary carboxymethylcellulose (CMC; $40 \mathrm{~g} / \mathrm{kg}$ ) added to a cooked rice-based diet on the presence of post-weaning colibacillosis in pigs after weaning (after McDonald et al. 2001a) (Proportion of pigs in groups with diarrhoea)

\begin{tabular}{lcccc}
\hline Diet & Day $7^{\star}$ & Day 8 & Day 9 & Day 10 \\
\hline Rice & $0 / 8^{\mathrm{a}}$ & $1 / 8^{\mathrm{a}}$ & $0 / 8^{\mathrm{a}}$ & $0 / 8^{\mathrm{a}}$ \\
Rice + low viscosity CMC & $5 / 8^{\mathrm{b}}$ & $3 / 8^{\mathrm{b}}$ & $4 / 8^{\mathrm{b}}$ & $4 / 8^{\mathrm{b}}$ \\
Rice + high viscosity CMC & $7 / 7^{\mathrm{b}}$ & $7 / 7^{\mathrm{b}}$ & $7 / 7^{\mathrm{b}}$ & $5 / 7^{\mathrm{b}}$ \\
$P$ value & $<0.05$ & $<0.05$ & $<0.05$ & $<0.05$ \\
\hline
\end{tabular}

a,b Values within a column with unlike superscripts were significantly different $(P<0.05)$.

*Day number is the number of days after weaning (weaning is day 1 ).

attach to the brush border of the small-intestinal villi, but also allow the bacteria to attach to the mucus lining the intestinal tract (Conway, 1994). Of particular interest is the fact that CMC adheres to and thickens porcine mucin (Rossi et al. 1996) and may also alter its composition. These events may enhance the ability of haemolytic E. coli to bind to the mucus lining the intestinal villi and cause diarrhoea.

Altered microbial activity has also been noted in other species in association with increased viscosity of the small intestinal contents (for example, Choct et al. 1996; Smits et al. 1998; Langhout et al. 2000). For example, E. coli numbers and total anaerobic counts in the ileum of chickens increased significantly with the addition of citrus pectin (Langhout, 1998), whilst total microbial counts (aerobic and anaerobic) increased in the duodenum and jejunum of chickens fed diets containing CMC (Smits et al. 1998). Wyatt et al. (1988) found that the addition of CMC in diets for rats failed to increase the density of bacteria in the caecal or colonic contents, but the bacterial populations changed significantly such that the aerobic bacteria, in particular E. coli, were more numerous in the large intestine.

Oligosaccharides and control of post-weaning colibacillosis. Some oligosaccharides, such as inulin and oligofructose, have been proposed as 'prebiotics' because of their potential to selectively stimulate growth of Bifidobacterium spp. within the human large intestine, suppress proliferation of potential pathogens (Gibson \& Roberfroid, 1995) and modulate a variety of human enteric conditions and diseases (Steer et al. 2000). Prebiotics are defined as 'nondigestible food ingredients that beneficially affect the host by selectively stimulating the growth and (or) activity of one or a limited number of bacteria in the colon, and hence improve host health' (Gibson \& Roberfroid, 1995).

Arising from work conducted in human subjects, and coupled to the withdrawal of growthpromoting antimicrobials, there has been interest in the use of selected oligosaccharides (nondigestible oligosaccharides; NDO) as prebiotics in the weaner pig. Since 1990, a considerable amount of work has been conducted in this field in the pig, but generally with equivocal results (Chesson \& Stewart, 2001). An exhaustive investigation into the effect of NDO in young pig diets on the microflora, fermentation characteristics and digestibility of nutrients was conducted in a doctoral thesis by Houdijk (1998). In essence, Houdijk (1998) reported no biologically significant effects on any indices measured in response to the NDO used (fructo-oligosaccharides and transgalacto-oligosaccharides). The effectiveness of prebiotics such as NDO will depend largely on the environments (for example, dirty, clean) under which pigs are kept, and may be masked by the pre-caecal digestion of such compounds. In addition, Mikkelsen \& Jensen (2001) reported that the populations of Bifidobacterium spp. in the gastrointestinal tract of pigs aged 2-4 weeks constituted less than $1 \%$ of the total bacterial population. It is difficult to 
imagine how even a $100 \%$ increase in numbers caused by feeding NDO could have a marked effect on intestinal health. Nevertheless, McDonald (2001), using weaned piglets naturally colonised by haemolytic E. coli, and Rossi et al. (2001), using isolated jejunal loops, both reported decreased proliferation of $E$. coli in response to inulin added to the diet.

Dietary oligosaccharides might also be generated in the gastrointestinal tract itself from polysaccharides that are more complex, and exert effects on gut function and bacterial dynamics. As discussed earlier, however, observing beneficial effects on amelioration of bacterial diseases might be compounded by the lack of any objective measure of microbial status of the gastrointestinal tract, and so it is often difficult to predict the response of the host's gut microflora to any additive, such as an oligosaccharide. In this regard, Reid \& Hillman (1999) proposed that an assessment of a pig's capacity to resist pathogens could be based on the faecal ratio of lactobacilli : coliforms in the gut contents, since lactic-acid bacteria are known to inhibit the growth of enterotoxigenic E. coli (Hillman et al. 1995). Although it could be argued that faecal populations and numbers do not represent those present in the small intestine, where $E$. coli attaches and causes disease, the lactobacilli:coliforms ratio suggests that a larger population of lactic-acid bacteria relative to coliforms provides some indication that enhanced numbers of those strains that are capable of inhibiting coliforms, including pathogens, might be present (Reid \& Hillman, 1999).

Resistant starch and post-weaning colibacillosis. Some recent studies in pigs have investigated the use of 'resistant starch' (RS; see below for definition) as a means of extending large-intestinal fermentation, such that the microflora (for example, Bacteroides spp.) do not use proteins as an energy source with the production of metabolites (for example, cadaverine, putrescine) that have been associated with diarrhoea after weaning (Aumaitre et al. 1995). The hydrolysis of starch granules by $\alpha$-amylase in the small intestine is not always complete. Starch that enters the caecum and colon is termed RS (Annison \& Topping, 1994; Baghurst et al. 1996). There are three main forms: (i) starch granules bound in the middle of a large food particle that are not physically accessible to digestive enzymes (RS1); (ii) starch granules resistant to degradation due to the crystalline structure within starch, such as that found in potato (RS2); (iii) some starches when heated and then cooled can reform (retrograde) in a type of crystalline structure that inherently resists digestion (RS3). Once in the large intestine, RS is degraded by the microflora, especially in the caecum (Pluske et al. 1998).

Reid \& Hillman (1999) found that differences existed in both protein degradation and bacterial counts in the colon of weaner pigs when different starches were fed. In vitro studies conducted previously by these authors (Reid et al. 1998) indicated that retrogradation of the amylose in starch caused resistance to bacterial degradation, an effect suggested to be the result of amylopectin 'coating' by the amylose. Reid et al. (1996) also showed that certain intestinal bacteria from pigs, such as Clostridium butyricum, might prefer to ferment the amylopectin fraction of starch rather than the amylose fraction, such that a starch lower in amylose would leave the amylopectin more accessible to the microflora. In addition, the $\alpha-1,-4,1-6$ structure of amylopectin should reduce the rate of fermentation, and hence extend fermentation along the intestinal tract. Reid \& Hillman (1999) found that protein fermentation in the mid- to distal colon was best reduced by inclusion of retrograded waxy maize, which also increased the lactobacilli : coliform ratio in these segments.

Liquid feeding and post-weaning colibacillosis. Considerable interest has arisen in the use of liquid feeding of pigs in the past 10 years. Liquid feeding has been used as a way not only of 
enhancing feed intake and growth rate, but also as a means of manipulating the microflora, both in the fermentation tank and the gastrointestinal tract, with the object of ameliorating enteric diseases (Brooks et al. 1996, 2001; Jensen, 1998; Geary et al. 1999; Mikkelsen \& Jensen, 2000). Fermented liquid feed (FLF) is characterised by high numbers of lactic acid bacteria, high numbers of yeast, a low $\mathrm{pH}(<4 \cdot 0)$, and a high concentration of lactic acid (132-244 mM) (only the undissociated form of lactic acid is bactericidal or bacteriostatic; Russell \& DiezGonzalez, 1998), and typically results in reduced numbers of coliform bacteria in the feed, provided fermentation conditions are correct. Lactic acid has antibacterial effects on E. coli and Salmonella species (Nout et al. 1989), and lactobacilli can inhibit adhesion of E. coli to the intestines (Hillman et al. 1994). For example, Beal et al. (2001) demonstrated that fermenting liquid feed at $37^{\circ} \mathrm{C}$ was an effective way of eliminating potentially pathogenic species such as E. coli, although at $20^{\circ} \mathrm{C}$ the antimicrobial effects of FLF were very much less apparent. This was possibly due to the expression of heat-shock proteins that enabled E. coli to withstand the antimicrobial effects of lactic acid (Phadtare et al. 1999). There were marked differences between $E$. coli strains in their ability to withstand the antimicrobial effects of FLF, suggesting that the effects of feeding FLF on pathogenic populations in the gastrointestinal tract might also be variable.

Nevertheless, FLF has been shown to alter populations of the microbiota in the intestines and influence volatile fatty acid (VFA) levels (Jensen, 1998; Jensen \& Mikkelsen, 1998; Mikkelsen \& Jensen, 2000; Moran et al. 2001). For example, Moran et al. (2001) showed that no coliform bacteria $\left(<3.0 \log _{10}\right.$ colony forming units $\left./ \mathrm{ml}\right)$ were detectable in the terminal ileum of pigs fed FLF, and reduced concentrations were found in the large intestine, in comparison to pigs fed dry feed or non-fermented liquid feed (Table 4). Moreover, the use of pre-fermentation (steeping) of the feed in water as a means of hydrolysing the soluble NSP before feeding is likely to reduce the viscosity induced by intact soluble NSP in cereals. This is because endogenous glycosidases in the grain have already begun the process of polysaccharide breakdown.

Use of exogenous enzymes and post-weaning colibacillosis. The use of in-feed enzymes for enhanced production and control of certain enteric conditions in chickens (for example, sticky droppings) is commonplace. In contrast, the generalised use of enzymes in pig diets is less common (Partridge, 2001), although they could offer potential for the amelioration of some enteric conditions and diseases. Unfortunately, there are few studies investigating the influence of supplementary enzymes on reducing enteric bacterial infections in pigs. It is difficult to imagine a direct effect of an exogenous enzyme per se on the gastrointestinal microflora; however enzymes might act in other ways.

There is recent interest in the use of supplementary enzymes to create oligosaccharides in situ from the hydrolysis of branched-chain NSP, such as arabinoxylans and xyloglucans, which might then influence the composition of the microbial flora. This has been coined the 'pre-pro-biosis' concept (Partridge \& Tucker, 2000). Certainly, Austin et al. (1999) reported the presence of a number of oligosaccharide configurations when a single cloned endo-1,4xylanase was used with different UK wheat cultivars, although the effects of these oligosaccharides in vivo were not investigated. Xylanase addition to broiler chicken diets resulted in a relative increase in Bifidobacteria spp. and Bacteroides spp., a response that might be expected due to an increase in xylo-oligosaccharides. The proportion of Lactobacillus spp., however, which might also be expected to increase in response to more xylo-oligosaccharides present, remained unchanged (Bedford \& Apajalahti, 2001). More recently, Fernandez et al. (2000) 
Table 4. Microbial counts ( $\log _{10}$ colony-forming units per $\mathrm{ml}$ ) and $\mathrm{pH}$ of the digesta in the terminal ileum, caecum and colon of pigs fed different diets after weaning at $23 \mathrm{~d}$ of age (after Moran et al. 2001)

\begin{tabular}{|c|c|c|c|c|}
\hline \multirow[b]{2}{*}{ Site along gastrointestinal tract } & \multicolumn{4}{|c|}{ Diet type } \\
\hline & FLF & NFLF & DF & $\mathrm{S}$ \\
\hline \multicolumn{5}{|l|}{ Ileum } \\
\hline $\mathrm{pH}$ & $6 \cdot 1$ & $6 \cdot 4$ & $6 \cdot 3$ & $5 \cdot 9$ \\
\hline Lactobacilli & $8 \cdot 8^{a}$ & $7 \cdot 0^{a}$ & $<3.0$ & $7 \cdot 3^{a}$ \\
\hline Coliforms & $<3.0$ & $8 \cdot 1^{a b}$ & $8 \cdot 5^{a}$ & $6 \cdot 0^{b}$ \\
\hline \multicolumn{5}{|l|}{ Caecum } \\
\hline $\mathrm{pH}$ & $6 \cdot 0$ & $6 \cdot 0$ & $5 \cdot 8$ & $6 \cdot 1$ \\
\hline Lactobacilli & $8.5^{a}$ & $8 \cdot 1^{\mathrm{a}}$ & $5 \cdot 5^{b}$ & $7 \cdot 3^{a}$ \\
\hline Coliforms & $5 \cdot 5^{a}$ & $7 \cdot 4^{a b}$ & $8 \cdot 4^{b}$ & $7 \cdot 5^{a b}$ \\
\hline \multicolumn{5}{|l|}{ Colon } \\
\hline $\mathrm{pH}$ & $6 \cdot 2^{a}$ & $6 \cdot 0^{a}$ & $5.9^{a}$ & $6 \cdot 6^{b}$ \\
\hline Lactobacilli & $8 \cdot 6^{a}$ & $7 \cdot 9^{a}$ & $5 \cdot 0^{b}$ & $8 \cdot 0^{a}$ \\
\hline Coliforms & $5 \cdot 6^{a}$ & $8 \cdot 1^{a}$ & $8 \cdot 6^{b}$ & $7 \cdot 3^{a}$ \\
\hline
\end{tabular}

FLF, fermented liquid feed; NFLF, non-fermented liquid feed; DF, dry feed; S, sows' milk.

a,b Values within a row with unlike superscript letters were significantly different $(P<0.05)$

reported that broiler chickens fed a wheat-based diet supplemented with xylanase (Avizyme $1300^{\circledR}$; Danisco Animal Nutrition, Marlborough, Wiltshire, UK) showed reduced viscosity and less Campylobacter jejuni in the caeca following experimental infection. Interestingly, this was associated with an increased number of neutral and sulfated mucins in goblet cells. Furthermore, Hampson et al. (2002) reported that 22-week-old laying hens experimentally infected with a virulent strain of Brachyspira intermedia and fed Avizyme 1302 ${ }^{\circledR}$ (Danisco Animal Nutrition) in a wheat-based diet showed reduced proliferation of this spirochaete in the caeca.

In relation to PWC, Inborr \& Ogle (1988) and Partridge \& Tucker (2000) reported a reduction in the frequency and severity of diarrhoea in weaned piglets fed diets supplemented with glycosidases. Chesson \& Stewart (2001), however, cautioned about the precise cause of the diarrhoea seen in such studies, and reinforced the need for microbiological assessment to examine the effect of, for example, oligosaccharides derived in situ. This is because the diarrhoea seen after weaning can be osmotic in nature rather than being of bacterial origin. Future studies in this area require alignment of dietary work and age of the pig with assessments of microbial populations to truly study the effects of enzymes and oligosaccharides on enteric bacterial diseases.

In addition, the response of the microflora to enzyme addition probably depends on the initial microbial status of the pigs, which in turn depends on the form and digestibility of the diet and the extent of the microfloral challenge it evokes. Since enzymes are likely to change substrate flow into the small and large intestines, the subsequent responses will vary according to the populations present at time of administration and their reaction to such changes (Bedford \& Apajalahti, 2001). It is not surprising that given the huge range of microfloral conditions likely to exist between studies, the responses to enzyme use, rather than being absolute, are a continuum or a population of responses varying from detrimental to highly positive. Nevertheless, many of the factors governing the extent of enzyme responses are most likely similar to those influencing responses to antimicrobials. For example, the response to antimicrobials in the diet depends to a large degree on the conditions animals are kept under. It is likely that any positive responses to enzymes will be dictated not only by the status of the microflora in the pig's 
gastrointestinal tract, but also by environmental, management and dietary factors such as cereal type and quality, and processing (Bedford \& Apajalahti, 2001).

Influence of protein sources on post-weaning colibacillosis. Certain components of weanling pig feeds, such as soyabean meal, have been implicated in causing intestinal mucosal damage and intestinal fluid accumulation in weaner pigs. When fed in creep feeds, it has been suggested that soya protein may act as a primer for hypersensitivity reactions after weaning that, in turn, predispose pigs to PWC (Miller et al. 1984). Evidence to support this notion is equivocal (Hampson, 1994; Dréau \& Lallès, 1999). The source of protein used has received some attention with regard to PWC, although again the evidence is confusing. Hampson (1987) reviewed the literature at the time, and reported research from several groups implicating the protein content and protein composition of the diet in the aetiology of PWC. For example, Prohászka \& Baron (1980) reported increased numbers of haemolytic E. coli in the small intestines of pigs that were fed $210 \mathrm{~g}$ $\mathrm{CP} / \mathrm{kg}$ as opposed to $130 \mathrm{~g} \mathrm{CP} / \mathrm{kg}$. Although a level of $130 \mathrm{~g} \mathrm{CP} / \mathrm{kg}$ would never be fed commercially, these data suggest that it might be possible to limit the extent of PWC by formulating diets with lower amino acid (protein) levels, or by using more digestible protein ingredients. Changing from skimmed milk powder to soyabean and maize increased the severity of diarrhoea and appearance of enterotoxigenic E. coli in 3-week-old pigs (Shimizu \& Terashima, 1982), although Pouteaux et al. (1982) found no difference in diarrhoea or bacterial populations when comparing buttermilk powder, soyabean meal and pea protein concentrate. Interestingly, Kiers $e t$ $a l$. (2001) recently reported that processed soyabean products, including mould-fermented soyabean (tempe), reduced the fluid and electrolyte loss (particularly sodium and chloride) in jejunal segments in the presence of enterotoxigenic $E$. coli.

In the case of the newly-weaned pig, typical starter diets contain $220-250 \mathrm{~g} \mathrm{CP} / \mathrm{kg}$, and apparent digestibility of this protein at the terminal ileum is $75-85 \%$. This results in a considerable amount of 'escape' (resistant) protein entering the large bowel. For instance, a $7 \mathrm{~kg}$ pig eating $300 \mathrm{~g} / \mathrm{d}$ of a $220 \mathrm{~g} \mathrm{CP} / \mathrm{kg}$ diet might be 'losing' 33-55 g protein daily to its hindgut. Protein is fermented rapidly by the microbiota with the production of diamines (for example, putrescine, cadaverine, tryptamine) and gases (for example, $\mathrm{NH}_{3}$ ) that have been implicated in the clinical expression of PWC (Aumaitre et al. 1995). Little attention, however, has been given to the digestion and metabolism of resistant protein by intestinal bacteria of pigs, and consequently knowledge of the proteolytic activities of gut bacteria in the pig is lacking. It is recognised, however, that a number of bacterial groups including Bacteroides, Clostridium, Enterobacterium, Lactobacillus and Streptococcus possess the ability to produce diamines, such as putrescine, cadaverine, histamine and tyramine, via decarboxylation of amino acids (for example, tyrosine, tryptophan, lysine) and breakdown of polyamines (Gaskins, 2001). Diamines have been implicated in the aetiology of PWC. In the 3-week-old weaned pig, for example, Porter \& Kenworthy (1969) observed that increased urinary heterocyclic amine excretion was associated with diarrhoea after weaning, with putrescine and cadaverine levels being particularly high. Porter \& Kenworthy (1969) commented that it is not likely to be the absolute amount of these amines produced, but their site of production, that might predispose to PWC. These workers found that the small intestine was the main site of amine production in severely diarrhoeic pigs, whereas in clinically unaffected pigs there was only a low level of amine production in the small intestine. Nollet et al. $(1999 a, b)$ reported protective effects against neonatal and PWC in piglets by feeding bovine plasma powder; however when the powder was included in the diet at $90 \mathrm{~g} / \mathrm{kg}$, diarrhoea attributable to biogenic amines was found.

Aumaitre et al. (1995) showed that the activity of major gut proteases (trypsin, chy- 
motrypsin) were stimulated after weaning by an increase in the level of CP in the weaning diet of up to, but not exceeding, $200 \mathrm{~g} / \mathrm{kg}$. This partially helps to explain data showing a decrease in the apparent ileal digestibility of $\mathrm{N}$ in pigs fed diets containing more than $225 \mathrm{~g} \mathrm{CP} / \mathrm{kg}$ ( $\mathrm{Li}$ et al. 1993). If this occurred, then the undigested protein would move distally and may be decarboxylated to amines that, in turn, could predispose the young pig to diarrhoea. In contrast to this notion, other authors (for example, Armstrong \& Cline, 1976; Pouteaux et al. 1982; Etheridge et al. 1984) failed to find any association between dietary protein source and the incidence of diarrhoea after weaning. Diets containing a large number of protein sources may increase the severity of diarrhoea compared with diets with fewer sources of protein (Etheridge et al. 1984). In addition, there are other possible reasons for these discrepancies between studies. Very few (if any) studies have used controlled infections, and most of the research has confounded protein type with protein level. Further investigations using controlled infection studies and defined protein sources are needed to separate these causative factors to assess their effects on intestinal health.

The bacterial products of protein fermentation are more likely to be produced in response to an acid environment, a process itself generated by rapid fermentation of soluble NSP (and possibly starch). An interaction might exist, therefore, between resistant protein and NSP in the aetiology of PWC. In this regard, Bolduan et al. (1988) and Aumaitre et al. (1995) commented that the appropriate addition of insoluble NSP sources might ameliorate PWC. Bolduan et al. (1988), for example, presented evidence showing that the production of diamines in the colon reduced linearly with an increase in the crude fibre content of a weaner feed (Fig. 1). Based on this work, it is possible that appropriate (slowly or moderately fermentable) NSP sources, such as wheat bran or beet pulp, may reduce PWC at a given dietary protein concentration. These substrates will also promote the physiological and functional development of the hindgut of the young pig. In turn, a shift towards acid fermentation based on these NSP could decrease the formation in the colon of diamines that have been implicated in the aetiology of PWC. This notion, however, needs to be considered in relation to the work described earlier (see p. 340) showing that feeding a very digestible diet based on cooked white rice is also protective against PWC. This is because the levels of acid formed in the hindgut of rice-fed pigs are markedly lower than those observed when sources of NSP are fed. Clearly, further research is required to identify appropriate cereal, fibre and protein sources and their interaction(s) on the pathogenesis of PWC, in addition to practices such as pre-fermentation and liquid feeding as have been discussed previously. Identification of such interactions and practices will assist in design of nutritional programmes that will reduce reliance on the use of growth-promoting antimicrobials in pig diets.

\section{Swine dysentery}

In many countries swine dysentery (SD) is one of the most economically important endemic bacterial diseases of swine. The disease is a mucohaemorrhagic colitis in grower (and sometimes weaner) pigs affecting the caecum, colon and rectum. SD is caused by the anaerobic spirochaete Brachyspira (Serpulina) hyodysenteriae (Harris et al. 1999). Clinical manifestations vary greatly, and include both mild and sub-clinical disease. In typical cases, infected pigs initially show a slight depression and reduced feed intake. They develop diarrhoea, which is grey to black and sometimes watery but is more often soft and porridge-like. This diarrhoea progresses to consist of mucus plugs, fibrin, epithelial cell casts, and flecks of fresh blood. Affected animals have faecal staining of the hindquarters, become dehydrated and appear 


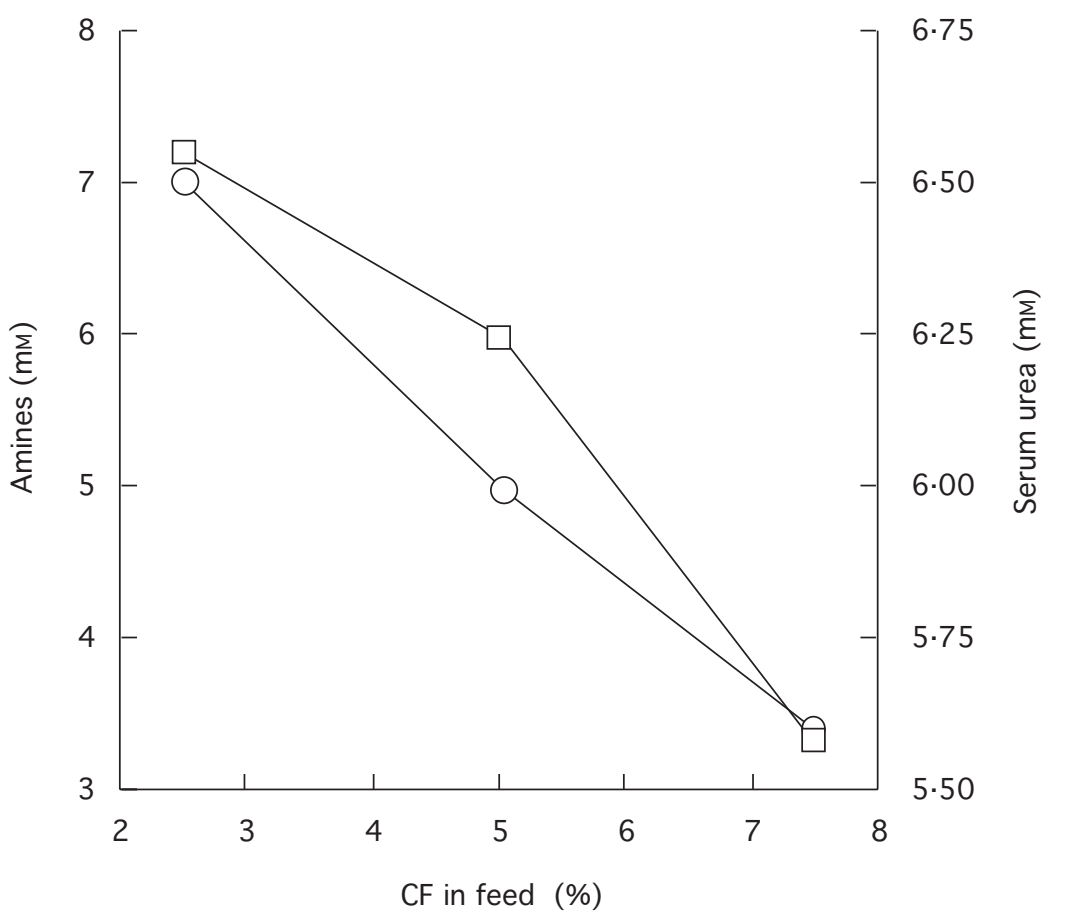

Fig. 1. Relationship between the dietary crude fibre (CF) content of the diet (achieved by adding wheat bran) fed to weaner pigs and the concentrations of diamines ( $\square$, cadaverine, putrescine, histamine and tryptamine) and serum urea (O) (from Bolduan et al. 1988).

gaunt, with a tucked-in abdomen and an arched back. If left untreated, around $10 \%$ of affected pigs can die within $5 \mathrm{~d}$ of first showing clinical signs (Hampson \& Trott, 1995).

The precise pathogenesis of SD is not well understood, though it is recognised that the disease does not always express itself clinically in pig herds despite the presence of the bacterium (Hampson et al. 1992). For example, a herd survey conducted in the state of Western Australia showed that $33 \%$ of herds were serologically positive for B. hyodysenteriae, yet little clinical disease was present (Mhoma et al. 1992). Many factors have been implicated in the aetiology of SD (for reviews, see Hampson \& Trott, 1995; Harris et al. 1999), however it is evident that nutrition may modulate the expression of the disease. The first report of such an influence was a retrospective study by Prohászka \& Lukács (1984), who found that a diet based on maize silage that lowered $\mathrm{pH}$ and increased VFA concentrations in the large intestine was apparently bactericidal to B. hyodysenteriae and reduced clinical expression of the disease (Table 5). These authors attributed the intensity of the antibacterial effect of the diet to the lower base value, and hence greater acidity (lower $\mathrm{pH}$ ) present in the large intestine.

Siba et al. (1996) attempted to replicate this work with pigs (25-30 kg live weight) that were experimentally inoculated with a virulent strain of $B$. hyodysenteriae after being fed diets designed to either promote or limit fermentation in the large intestine. In contrast to the expectations based on the work of Prohászka \& Lukács (1984), Siba et al. (1996) found that a diet based on cooked white rice and (predominately) animal protein ingredients (for example, bloodmeal, meat and bone meal) reduced the degree of hindgut fermentation and reduced both the proliferation of $B$. hyodysenteriae and clinical expression of the disease. A diet based on 
Table 5. A comparison of physiological variables between pigs free from swine dysentery (SD) and pigs clinically affected with the spirochaete. A total of thirty clinically healthy pigs were sampled from each group (from Prohászka \& Lukács, 1984) (Mean values and standard deviations)

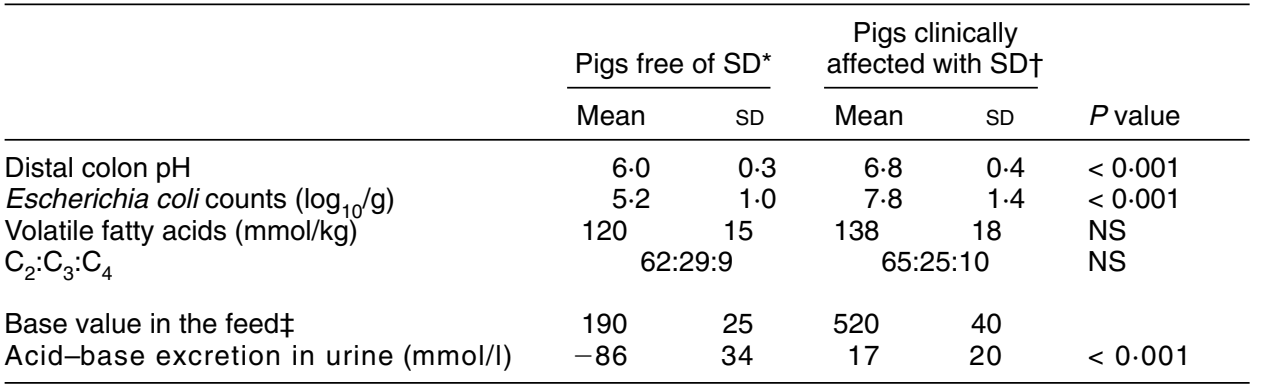

*Diet fed to pigs contained (g/kg diet): maize, 620; barley, 200; soyabean meal, 120; meatmeal, 30 (150 $\mathrm{g} / \mathrm{kg}$ crude protein content in diet).

†Diet fed to pigs contained (g/kg diet): silage, 600; wheat, 250; soyabean meal, 120 (140-150 g/kg crude protein content in diet).

‡Determined as the bicarbonate load resulting from consumption of $1 \mathrm{~kg}$ of feed.

wheat, barley and Australian sweet lupins that promoted hindgut fermentation (as evidenced by lower $\mathrm{pH}$, increased VFA levels, heavier organ weights) caused the highest incidence of SD.

Subsequent experiments in our laboratory (Pluske et al. 1996, 1998) confirmed these findings, and have demonstrated that a diet low in both soluble NSP and RS concentrations generally affords protection against $B$. hyodysenteriae following experimental infection. Diets using rice, sorghum and maize as the sole cereal source appear to be more protective than diets based on wheat, barley and dehulled oats (groats). However, the manner in which the grains have been processed also appears to be important, especially with cereals inherently low in NSP $(<1 \mathrm{~g} / 100 \mathrm{~g}$ soluble NSP). Our data suggest that a reduction in RS levels (for example, via extrusion, steam flaking) will only prove effective against SD if the grain in question has an inherently low NSP level to begin with.

Whilst we have shown that the microbial digestion of fermentable carbohydrates in the large intestine facilitates the expression of $\mathrm{SD}$, our research has provided few insights into the underlying mechanisms. It is evident that the varied expression of SD with different diets extends beyond a simple effect of fermentation per se. For example, Pluske et al. (1996) failed to show any relationships between fermentation indices (for example, $\mathrm{pH}$, VFA levels) and the incidence of SD. Furthermore, Pluske et al. (1998) showed no association between ATP levels (an indicator of microbial activity) in the large intestine and expression of the disease. Pigs fed a viscous NSP source (guar gum), for instance, showed the highest incidence of SD, low $\mathrm{pH}$ levels and high VFA concentrations, yet the lowest ATP levels.

Numerous hypotheses have been proposed in an attempt to explain these dietary effects on SD. These include factors such as the DM content of colonic contents influencing the survival of spirochaetes (Siba et al. 1996), factors affecting the mobility of the spirochaete in the mucosal lining, diet-induced changes in chemotaxic-regulated motility (Kennedy et al. 1988), factors affecting the ability of $B$. hyodysenteriae to express haemolysins and/or lipopolysaccharides and cause inflammation of the epithelium, and the $\mathrm{Zn}$ content of the diet (Zhang et al. 1995). More recently, Durmic et al. $(1998,2000)$ reported changes in composition of the hindgut microflora associated with feeding different diets in association with SD. It has long been recognised that other bacterial species, such as Fusobacterium spp., Clostridium spp. and Bacteroides spp. must be present for SD to occur (Meyer et al. 1975; Whipp et al. 1979). 
Durmic et al. $(1998,2000)$ showed differences between diets in the genera and species present in the large intestine, with changes in bacterial populations consistent with those that occur in the natural disease. However, Leser et al. (2000), using 16S ribosomal DNA sequence analysis, did not detect the same synergistic bacteria in pigs infected with $B$. hyodysenteriae, although they did report changes in bacterial populations when pigs were fed either a cooked rice diet or a FLF following infection with the causative agent. Furthermore, and in contrast to our data, Kirkwood et al. (2000) and Leser et al. (2000) did not find a protective effect of feeding a parboiled cooked rice-animal protein diet following experimental infection of pigs with $B$. hyodysenteriae. Possible reasons for the disparate results between laboratories include differences in B. hyodysenteriae strains or virulence factors, variation in diet ingredients and preparation of the rice, and variation in the microflora composition of the hindgut in pigs in the different countries.

An area of research not yet explored in relation to nutritional effects on SD is that of dietary protein content and type. Given the postulated effects of excess protein entering the caecum and colon on bacterial proliferation and production of bacterial metabolites, it is feasible that this component of the diet might also influence the aetiology of SD. This has particular relevance for some countries where many animal protein sources have been banned from diets fed to grow and finish pigs, and only vegetable proteins are available to the feed manufacturer. Studies, for example, to examine possible effects of processing (for example, extruded peas), protein types (for example, soya protein isolate), and appropriate enzyme combinations (for example, proteases plus glycosidases) appear to be warranted in relation to susceptibility to SD.

Enzymes and swine dysentery. Given the purported role of certain carbohydrates in the expression of SD, a logical progression of this work was to examine whether glycosidases added to the diet could reduce the incidence of the disease. In an experimental model of SD, Durmic et al. (2000) used an in-feed arabinoxylanase in an attempt to ameliorate the incidence of SD by hydrolysing glycosidic linkages of soluble NSP before their passage into the large intestine. The hypothesis that a reduced load of fermentable substrate entering the large intestine would reduce the incidence of SD was tested in a study comprising a $2 \times 2$ factorial arrangement of treatments. Wheat was fed to pigs either in extruded form (to reduce the contribution of RS to the expression of SD) or hammer-milled form, and an exogenous arabinoxylanase was added or not added to the diet. Pigs were infected with a virulent strain of $B$. hyodysenteriae at a body weight of around $25 \mathrm{~kg}$, and subsequently monitored for expression of the disease.

Both the extrusion of wheat and addition of arabinoxylanase increased pre-caecal starch digestion, as judged by reduced starch levels in the large intestine (Table 6). Addition of arabinoxylanase to the diet did not reduce the incidence of SD. The failure of extrusion and the enzyme to protect against SD might be related to the apparent increased fermentation in proximal areas of the hindgut, as judged by an increase in bacterial ATP concentrations (Table 6). A significant main effect of enzyme addition on digesta $\mathrm{pH}$ was seen, but only in the distal part of the colon, such that pigs fed arabinoxylanase in their diet had a higher $\mathrm{pH}$ than pigs not fed enzyme $(6 \cdot 68 v .6 \cdot 35, P=0 \cdot 017)$. These data suggest that by the time the enzyme had cleaved the arabinoxylan chains, and the digesta had reached the distal colon, there was little or no fermentable carbohydrate remaining and protein fermentation was occurring. Passage of smaller NSP molecules may have then allowed colonisation by B. hyodysenteriae in the anterior parts of the hindgut by providing suitable types and levels of substrate, with subsequent expression of SD. In this study, therefore, use of an enzyme targeting wheat NSP exacerbated the incidence of SD. 
Table 6. Production data, large intestinal fermentation indices, and incidence of swine dysentery (SD) in pigs fed wheat-based diets subject to different processing and addition of arabinoxylanase (after Durmic et al. 1998) (Mean values and standard errors of the difference)

\begin{tabular}{|c|c|c|c|c|c|c|c|c|}
\hline & \multicolumn{4}{|c|}{ Diet type } & \multirow[b]{2}{*}{ SED } & \multicolumn{3}{|c|}{ Significance } \\
\hline & RW & ExtW & RW-Enz & ExtW-Enz & & $W$ & Enz & $W \times E n z$ \\
\hline Growth rate $(g / d)$ & 427 & 430 & 489 & 423 & $33 \cdot 8$ & NS & NS & * \\
\hline \multicolumn{9}{|l|}{ Starch $(\mathrm{mg} / \mathrm{g})$} \\
\hline Proximal colon & $10 \cdot 2$ & 0.6 & $6 \cdot 2$ & $2 \cdot 0$ & 2.52 & $* * *$ & NS & * \\
\hline $\mathrm{pH}^{\text {Distal colon }}$ & $7 \cdot 2$ & 0.2 & $2 \cdot 1$ & 0.0 & 2.97 & $* *$ & NS & NS \\
\hline Proximal colon & $5 \cdot 7$ & $6 \cdot 1$ & $5 \cdot 7$ & $6 \cdot 0$ & 0.34 & NS & NS & NS \\
\hline Distal colon & $6 \cdot 1$ & $6 \cdot 6$ & $6 \cdot 6$ & $6 \cdot 8$ & 0.30 & $\star *$ & * & NS \\
\hline \multicolumn{9}{|l|}{ ATP $(\mathrm{nmol} / \mathrm{g})$} \\
\hline Proximal colon & 0.30 & 0.10 & 0.42 & 0.44 & 0.26 & NS & * & NS \\
\hline Distal colon & 0.18 & 0.14 & 0.17 & 0.23 & 0.18 & NS & NS & NS \\
\hline Incidence of SD (\%) & $66 \cdot 7$ & $33 \cdot 3$ & 100 & 100 & - & - & - & - \\
\hline
\end{tabular}

RW, raw wheat; ExtW, extruded wheat; RW-Enz, raw wheat + enzyme; ExtW-Enz, extruded wheat plus enzyme; W, wheat.

${ }^{*} P<0.05,{ }^{* *} P<0.01,{ }^{* *} P<0.001$.

\section{Porcine intestinal spirochaetosis}

The terms porcine intestinal spirochaetosis (PIS) or spirochaetal diarrhoea have been used to describe colitis of growing pigs associated with infection of the large intestine with the weakly $\beta$-haemolytic intestinal spirochaete Brachyspira (Serpulina) pilosicoli (Trott et al. 1996). Infection is characterised by the attachment of $B$. pilosicoli to the colonic epithelium, followed by disruption of the microvilli and, in some cases, local invasion and necrosis of the epithelium. This results in patchy colitis, excess mucus production and the passage of watery, mucoid, and occasionally blood-flecked diarrhoea. Clinically, pigs lose body condition, appear ill-thrifty, have perineal staining and a tucked-up appearance. Pigs initially pass loose, sticky faeces, which develops into diarrhoea with a consistency of wet cement. In weaner or grower pigs the diarrhoea is usually watery to mucoid, green or brown, and can contain tags of mucus and flecks of blood (Hampson \& Trott, 1995, 1999). Pigs do not often die of this infection, which may occur as a primary or secondary invader of the large intestine.

Given the close similarity between $B$. pilosicoli and $B$. hyodysenteriae, their very similar habitats in the hindgut, and reports from veterinarians in the field of dietary influences on PIS, an investigation was made into whether the cooked rice diet that protected pigs from SD might also protect from PIS (Hampson et al. 2000). Two groups of weaner pigs were fed either a standard commercial wheat-lupin weaner diet $(n 8)$ or a highly digestible diet based on cooked white rice and animal protein sources $(n 6)$ for 3 weeks after weaning. All pigs were then challenged orally over $3 \mathrm{~d}$ with $10^{10}$ active mid-log phase cells of a field strain of $\mathrm{B}$. pilosicoli (strain 95/1000). The pigs were killed 3-4 weeks post inoculation. All animals became colonised with $B$. pilosicoli strain $95 / 1000$, but this occurred later (mean of $10 \mathrm{~d}$ compared with $3 \mathrm{~d}$ post inoculation, $P<0.001$ ), and lasted for less time (mean of $5 \mathrm{~d}$ compared with $16 \mathrm{~d}, P<$ $0 \cdot 001$ ), in the pigs fed the cooked white rice-animal protein diet compared with those fed the wheat-lupin-based diet. One pig fed the wheat-lupin diet developed an acute and severe erosive colitis with severe watery diarrhoea within $3 \mathrm{~d}$ post inoculation, and was euthanased. All the other pigs on both diets developed mild transient diarrhoea, lasting only 2-3 d. Small areas of mild patchy colitis were observed at post mortem, but no spirochaete attachment to the epithelium was detected. This study demonstrated that, as with B. hyodysenteriae in grower 
pigs, colonisation by $B$. pilosicoli could be influenced by diet. In this case, the rice-based diet did not prevent colonisation but only retarded it. In contrast with regard to the type of diet fed, but with a similar outcome, Stege et al. (2001) reported that the provision of straw in pens for finishing pigs was associated with a reduced prevalence of weakly $\beta$-haemolytic spirochaetes. In support, Pluske et al. (1998) reported a low incidence of SD when oaten chaff (a largely insoluble source of NSP) was fed to experimentally infected pigs.

DE McDonald, DW Pethick and DJ Hampson (unpublished results) showed that inclusion of CMC in a diet based on cooked white rice for pigs aged 5-6 weeks of age increased digesta viscosity and caused an increase in the duration of shedding of $B$. pilosicoli following experimental infection with the organism. The CMC also increased the duration of diarrhoea. The number of days that faecal swabs were positive for B. pilosicoli in pigs fed the rice-based diet without CMC ( 1.5 out of $9 \mathrm{~d}$ tested) was identical to that described in rice-fed pigs by Hampson et al. (2000), indicating consistency across experimental trials. In the same study by Hampson et al. (2000), the number of positive faecal shedding days for pigs fed a standard commercial diet based on wheat, barley and Australian sweet lupins was 5·3, a value not dissimilar from that recorded in pigs fed rice plus CMC by DE McDonald, DW Pethick and DJ Hampson (unpublished results) $(4 \cdot 2 \mathrm{~d})$. The similarity between the duration of shedding of $B$. pilosicoli in pigs in these two studies suggests that inclusion of CMC exerts physicochemical properties in the gut similar to that seen when a commercially-based diet is fed, further reinforcing the role of viscosity per se as a causative factor in the aetiology of PIS.

Non-specific colitis. Before the description of PIS and its association with B. pilosicoli, certain cases of what were almost certainly PIS were described as 'grower scour/non-specific colitis' (Smith \& Nelson, 1987). Such cases are still reported in the literature (for example, see Thomson et al. 1998; Johnston et al. 2001). Connor (1992) reported that non-specific colitis was influenced by diet, with pelleting of the diet and wheat-based diets believed to predispose pigs to the condition. The incidence of 'non-specific colitis' can be reduced by using an in-feed arabinoxylanase (Partridge, 1998), suggesting that NSP might play a role in this enteric condition. Processing of cereal grains at high temperature can change the structure of NSP, with Pluske et al. (1996) showing chemically that extrusion increased the soluble:insoluble NSP ratio in wheat, but decreased the RS content markedly. Working with barley-based diets but in $78 \mathrm{~kg}$ pigs, Fadel et al. (1988) showed that extrusion caused a shift from insoluble NSP to soluble NSP, and insoluble $\beta$-glucans to soluble $\beta$-glucans. The shift from insoluble to soluble NSP after extrusion cooking resulted in increased digestion of soluble NSP at the ileum (proportionally 0.54 more) and increased fermentation of insoluble NSP in the lower tract (proportionally 0.56 more). Moreover, Robertson et al. (1997) reported similar changes in barley when it was cooked at various temperatures up to $100^{\circ} \mathrm{C}$. Pelleting diets is known to solubilise some of the NSP in cereals (Pluske et al. 2001), and may cause starch retrogradation upon drying and cooling.

With extrusion and/or pelleting, it is possible that the major site of digestion in the gastrointestinal tract shifts from being predominately pre-ileal to post-ileal, in the caecum and colon. An increased rate of fermentation of carbohydrates in the hindgut most likely creates a favourable environment for the growth of $B$. pilosicoli and attachment to the colonic epithelium, and contributes to this condition. Greater digestibility of carbohydrates before the caecum is desirable, because entry of substrate into the hindgut might promote the proliferation of this particular pathogen. Alteration of the site of digestion of grains, therefore, by judicious grain selection and processing methodology may ameliorate the incidence of PIS. Even in the 
absence of the spirochaete, vigorous fermentation of undigested starch in the large intestine might generate sufficient hydrogen ion concentrations to damage the epithelium and cause a 'non-specific colitis'. In this regard, histological examination of the hindgut tissue might provide valuable evidence of inflammatory reactions that might predispose pigs to this condition.

Work in progress by the Meat and Livestock Commission (UK) (D Armstrong, personal communication) reported that $38 \%$ of farms surveyed had non-specific colitis, with $42 \%$ of farms reporting an infectious colitis. Of these, B. pilosicoli was isolated from $58 \%$ of farms, Lawsonia intracellularis (the agent of proliferative enteropathy) was isolated from $37 \%$ of farms, and Yersinia pseudotuberculosis and Yersinia enterocolitica (yersiniosis) were both isolated from $21 \%$ of farms. Earlier, Thomson et al. (1998) investigated the possible causes of colitis and typhlocolitis on eighty-five pig units in the UK between 1992 and 1996, and reported that $B$. pilosicoli was the primary agent on $25 \%$ of farms. This bacterium also formed part of mixed infections on another $27 \%$ of farms, with the main co-infections being Y.pseudotuberculosis, proliferative enteropathy (see pp. 354 and 355), Salmonella species or B. hyodysenteriae. Pathogens were not detected on $7 \%$ of farms despite colitis being present. The high incidence of mixed infections on pig farms poses a problem for the nutritional control of enteric pathogens, because it is unlikely that all pathogens will respond in the same way to dietary interventions.

\section{Salmonellosis}

Salmonella infections are a concern for the pig industry for two major reasons: (1) clinical disease (salmonellosis); (2) infection of pigs with Salmonella spp. serotypes that can be a source of infection on pork products. In contrast to the large number of serotypes isolated from carcasses and pork products, disease in swine is almost always caused by either the $\mathrm{H}_{2} \mathrm{~S}$-producing variant of $S$. choleraesuis var. Kunzendorf (manifest as septicaemia) or by S. enterica var. Typhimurium (Schwartz, 1999). A variety of serotypes may be isolated from diarrhoeic piglets immediately after weaning, but Schwartz (1999) remarked that most were associated with poor hygiene, concurrent enteric pathogens, inappropriate diets and a poor environment. Salmonella heidelberg has been associated with PWC, with lesions more typical of enterotoxigenic diarrhoeal disease than salmonellosis (Reed et al. 1985).

Causes of salmonellosis appear to be many and, as with many diseases, infection of pigs is more common than overt disease. A survey conducted recently in the USA (Harris et al. 1997) reported that salmonellae were isolated from the feed or feed ingredients from fourteen out of thirty farms and thirty-six out of 1228 samples, with isolation from pelleted feeds being more frequent than that from ground (mash) feed. In addition, isolation of salmonellae from feed was associated with the lack of bird-proofing, on-farm feed preparation, and with housing of pigs in facilities other than total confinement (Harris et al. 1997). Currently the major form of control and prevention of salmonellosis is the use of antimicrobial compounds, although Schwartz (1999) commented that nutritional approaches to preventing or alleviating the disease included feeding of propionic or other VFA (to lower gastric $\mathrm{pH}$ ) and supply of mannose, heavy metals, lactose and probiotics. Evidence to support these claims was not presented.

Of recent interest is a US study by Anderson et al. (2001), who reported that oral administration of a sodium chlorate solution $8 \mathrm{~h}$ and $16 \mathrm{~h}$ after a Salmonella enterica var. Typhimurium challenge in weaned pigs reduced caecal concentrations of the organism. Salmonella possess respiratory nitrate reductase activity that also catalyses the intracellular reaction of chlorate, an analogue of nitrate, to cytotoxic chlorite. Most other gastrointestinal anaerobes do not possess 
respiratory nitrate reductase. Anderson et al. (2001) proposed that such a nutritional treatment could be used before transport to the abattoir or in the drinking water during lairage as a way to reduce Salmonella carriage onto carcasses. Work by DJ Hampson and DW Pethick (unpublished results) at Murdoch University showed that feeding $7 \mathrm{~kg}$ weaner pigs a cooked white rice-animal protein diet in association with oral inoculation with Salmonella enterica var. Typhimurium delayed the onset of faecal colonisation (as assessed by plate counts) compared with pigs fed a wheat-based diet higher in NSP.

As discussed earlier (p. 344), FLF has been shown to influence the bacterial ecology of the gastrointestinal tract of pigs (Mikkelsen \& Jensen, 2000), particularly in relation to members of the family Enterobacteriaceae, and including Salmonella spp. For example it has been reported that units adopting liquid feeding of by-products or using FLF have a lower incidence of salmonellosis than herds using dry feed (Stege et al. 1997; Van der Wolf et al. 1999). Van Winsen et al. (2001) recently reported that the numbers of Enterobacteriaceae along the gastrointestinal tract were lower in pigs fed FLF compared with dry feed. These authors also reported a significant negative correlation between the concentration of undissociated lactic acid and Enterobacteriaceae numbers. Nevertheless, because other issues apart from specific dietary components may be contributing to the effects, information from such studies needs to be confirmed by careful experiments conducted under controlled conditions. For example, in the case of salmonellosis, the relative hygiene of the various diets may be influencing the infectious dose presented to the pigs, rather than the diet itself having protective effects in the gastrointestinal tract (Hampson et al. 2001). Consequently, numerous countries have now instigated strict quality assurance schemes in their feed manufacturing industries to limit the contamination of animal feed with Salmonella.

\section{Porcine proliferative enteropathies}

Porcine proliferative enteropathies (PPE; also known as proliferative ileitis) are a group of acute and chronic conditions of widely differing signs but with a common underlying pathological change visible at necropsy: a thickening of the mucosa of the small intestine and colon. The affected tissues show a proliferation of immature epithelial cells of the crypts, forming a hyperplastic to adenoma-like mucosa. These proliferating cells invariably contain numerous intracytoplasmic Lawsonia intracellularis, a Gram-negative, obligate intracellular bacterium (McOrist \& Gebhart, 1999). In growing pigs with uncomplicated proliferation of the mucosa, the condition is chronic proliferative enteropathy (or porcine intestinal adenomatosis, or ileitis). A variety of Campylobacter species have been recovered from proliferative lesions, but these are thought to be secondary agents in the condition (McOrist \& Gebhart, 1999). The main clinical signs of PPE include loose, watery stools with or without blood, puddled faeces with undigested feed, gauntness, and lack of weight-gain uniformity. Clinical signs often appear after stressful events (for example, moving, mixing, transport), with pigs aged 6-20 weeks more commonly affected than pigs younger than 6-8 weeks of age (Knittel, 1999).

PPE is widespread throughout the world, with surveys indicating that the percentage of herds infected varies between 3 and $94 \%$ (for example, Chang et al. 1997; Kim et al. 1998; Thomson et al. 1998; Pearce, 1999a,b; Stege et al. 2000). In Denmark, for example, Stege et al. (2000) reported that the prevalence of $L$. intracellularis in 1580 faecal samples was $93.7 \%$, with $32 \%$ of all farms surveyed having $L$. intracellularis as the only causative agent of infection. In contrast, a UK survey (Thomson et al. 1998) reported that L. intracellularis was the primary infective agent and cause of colitis on $3.5 \%$ of herds examined, although it was associated 
with a mixed infection where B. pilosicoli was the primary causative agent in $15 \%$ of farms. The use of antibiotics against L. intracellularis is the most common form of control, however McOrist \& Gebhart (1999) commented that acute and chronic PPE remains a major problem even in high-health status, minimal-disease herds.

A survey by Stege et al. (2001) aimed at identifying risk factors for infection with L. intracellularis showed that home-mixed (and/or non-pelleted) feed was associated with a reduced prevalence of the pathogen (as well as of weakly $\beta$-haemolytic spirochaetes). Pearce (1999b) provided evidence that the prevalence of L. intracellularis in UK pig herds was strongly related to infection with the endo-parasite Trichuris suis. In turn, herds that were fed relatively high levels of NSP in their grower diets (i.e. in the top $25 \%$ of levels in all herds studied) were twenty-seven times more likely to be infected with this nematode. Similar observations with regard to endo-parasites in pigs have been made in Denmark (Petkevicius et al. 1997). Pearce (1999b) concluded that the control of NSP intake for growers was the most important factor controlling parasite infection in grower-finisher pigs in the UK. Although not pertinent to infection by L. intracellularis per se, these data support the work of Stege et al. (2001) that the prevalence of L. intracellularis might be influenced by diet, although whether this is a direct effect or by modulation of other gastrointestinal organisms remains in question. In this respect, it is interesting to speculate on the possible role of dietary formation of butyrate and cell turnover as a potential modulator of the time available for intracellular Lawsonia to proliferate. Furthermore, Møller et al. (1998) commented that while the presence of L. intracellularis can be predictive of the diarrhoeic status of a pig herd, it does not warrant the conclusion that $L$. intracellularis is necessarily causing the diarrhoea.

\section{Gastric ulcers}

Ulceration of the pars oesophagea of the stomach of pigs is frequently detected at slaughter, and these lesions are sometimes thought to cause reduced weight gain to slaughter (Ayles $e$ al. 1996). Ulceration of the stomach is also a serious welfare issue. Ulcers may lead to perforation of the stomach wall and to peritonitis, as well as haemorrhaging. Such problems are considered a common cause of sudden death in grower pigs and sows (Friendship, 1999). A myriad of factors are implicated in the aetiology of gastric lesions, including low levels of dietary fibre, transportation stress, feed restriction, pelleting of the diet, physical crowding, pig genetics, feed particle size and so on. Recent studies from Brazil have shown a positive relationship between the presence of the spiral bacterium Helicobacter heilmannii in the pig's stomach and the occurrence of gastric ulcers. This organism was present in $100 \%$ of all slaughtered pigs showing ulcers, but only in $35 \%$ of macroscopically normal stomachs (Barbosa et al. 1995; Queiroz et al. 1996).

A considerable body of information exists in the literature describing the effects of cereal type, processing method and particle size on the prevalence of gastric ulceration. A large number of these studies originate from the USA and so have used maize as the base cereal (for example, Healy et al. 1994; Wondra et al. 1995a,b; Lawrence et al. 1998; Eisemann \& Argenzio, 1999; Regina et al. 1999). It is possible that the influence of particle size and processing method in maize-based diets on the expression of gastric ulceration differs from what might occur if wheat-, barley- and/or sorghum-based diets were fed to pigs, as would happen under Australian and European conditions.

In contrast to studies using maize, there are fewer reports investigating the effects of other cereals such as wheat, barley and sorghum on the prevalence of ulcers in pigs, although inter- 
est in this area has increased markedly in the last 5-10 years. Danish work reported by Nielsen \& Ingvartsen $(2000 a)$ found that pigs receiving rolled barley $(50 \%$ of particles $>1 \mathrm{~mm}$ ) or wheat in non-pelleted form had virtually no gastric lesions as opposed to pigs receiving ground ( $3 \mathrm{~mm}$ screen size) barley or wheat. Interestingly, rolled barley could be pelleted without causing gastric lesions whereas rolled, pelleted wheat resulted in the highest gastric lesion score. Ground wheat in pelleted form resulted in the highest gastric lesion scores. In another study, Nielsen \& Ingvartsen $(2000 b)$ found that pigs receiving either straw bedding (that they could consume) or rolled barley had a lower incidence of gastric ulceration in comparison with pigs receiving straw bedding where the cereal was finely ( $3 \mathrm{~mm}$ screen) ground. In all instances, groups of pigs having few ulcers had a higher stomach DM content. Ange et al. (2000) compared a maize-soyabean-based diet fed as a finely ground and pelleted diet $v$. a coarsely-ground and mash diet, and reported that the average daily water: feed ratio was higher for pigs on the pelleted diet $(4 \cdot 21 \mathrm{litres} / \mathrm{d} v .3 \cdot 04 \mathrm{litres} / \mathrm{d}, P=0 \cdot 02)$. Ange et al. (2000) suggested that the higher ratio for the pelleted diet might be the cause of a more fluid digesta allowing reflux of irritants (for example, $\mathrm{H}^{+}$, bile acids) from the distal stomach to damage the pars oesophagea. Lang et al. (1998) and Ange et al. (2000) associated decreased pH in the proximal stomach with increased prevalence of ulcers. In another US study, Mavromichalis et al. (2000) reported that wheat ground to an average particle size of $400 \mu \mathrm{m}$ supported improved gain:feed and faecal digestibilities of nutrients (ileal digestibilities were not reported) compared with a particle size of $600 \mu \mathrm{m}$, but also increased the incidence of stomach keratinisation and lesions in finishing pigs (Table 7).

A possible reason for differences seen between wheat and barley in the Danish work of Nielsen \& Ingvartsen (2000a) might be the degree of gelatinisation and retrogradation of starch (i.e. RS) that occurred after pelleting and drying and cooling. These interactions could be examined by comparing grains that differ in their amylose:amylopectin ratio, and that behave differently in vivo after processing. In addition, we are unaware of any reports investigating the extent of cell-wall rupture that occurs when grain is rolled, and how this compares with grain

Table 7. The influence of enzyme supplementation and particle size on the extent of keratinisation and ulceration in pigs fed wheat-based diets between 63 and $115 \mathrm{~kg}$ live weight (after Mavromichalis et al. 2000)

\begin{tabular}{|c|c|c|c|c|c|}
\hline \multirow[b]{2}{*}{ Particle size . . . } & \multicolumn{2}{|c|}{ No enzyme } & \multicolumn{2}{|c|}{ Enzyme } & \multirow[b]{2}{*}{ Statistical contrast* } \\
\hline & $600 \mu \mathrm{m}$ & $400 \mu \mathrm{m}$ & $600 \mu \mathrm{m}$ & $400 \mu \mathrm{m}$ & \\
\hline \multicolumn{6}{|l|}{ Stomach keratinisation } \\
\hline No. of observations & 38 & 35 & 33 & 36 & \\
\hline Normal & 26 & 4 & 24 & 2 & \\
\hline Mild & 6 & 12 & 7 & 18 & \\
\hline Moderate & 6 & 8 & 2 & 7 & \\
\hline Severe & 0 & 11 & 0 & 9 & \\
\hline Mean score $†$ & 0.47 & $1 \cdot 74$ & 0.33 & $1 \cdot 64$ & $P<0.01$ \\
\hline \multicolumn{6}{|l|}{ Stomach ulceration } \\
\hline No. of observations & 38 & 35 & 33 & 36 & \\
\hline Normal & 37 & 21 & 33 & 30 & \\
\hline Erosion & 1 & 10 & 0 & 2 & \\
\hline Ulcer & 0 & 2 & 0 & 4 & \\
\hline Severe ulcer & 0 & 2 & 0 & 0 & \\
\hline Mean score & 0.03 & 0.57 & 0 & 0.28 & $P<0.01$ \\
\hline
\end{tabular}

* Contrast between particle sizes of $600 \mu \mathrm{m} v .400 \mu \mathrm{m}$.

† Scoring system: 0 , normal; 1 , mild; 2 , moderate; 3 , severe keratosis.

‡ Scoring system: 0 , normal; 1 , erosion; 2 , ulcer; 3 , severe ulcer. 
that has been hammer-milled. Microscopic examination of grains comminuted by these two methods might provide insights into the extent of starch availability, and how this impacts upon the prevalence of gastric ulcers.

Regina et al. (1999) postulated that compounds secreted in the distal stomach and that return to the proximal stomach in finely ground diets may play a role in initiating damage to the stratified squamous epithelium of this region. Eisemann \& Argenzio (1999) reported that the generation of hydroperoxidases and stimulation of the antioxidant and prostaglandin defence systems were greater in growing pigs fed a finely ground, maize-soyabean meal diet. Studies in our laboratory have looked for a possible link between diet and bacterial activity in the aetiology of ulceration in the pars oesophagea. A weaner model of stomach ulceration was developed in which weaner pigs fed finely ground wheat developed quite severe ulceration after 2-3 weeks, whilst pigs fed the same wheat that had been subjected to high pressure and temperature extrusion did not develop lesions (Accioly et al. 1998). Protection was associated with the absence of the urease-producing $H$. heilmannii in the stomach. It is possible that interactions with dietary components that lead to gastric ulcers extend beyond factors such as particle size and processing, although these appear to be definite risk factors. These interactions might include, for example, the interplay between the degree of starch disappearance before the duodenum, the products of fermentation and the commensal stomach flora. We are aware of no studies that have attempted to quantify starch fermentation in the stomach. In this regard, Krakowka et al. (1998) postulated that production of organic acids from certain carbohydrates by Lactobacillus spp. and Bacillus spp. in the stomach was a risk factor for gastric ulceration. This possibility would appear to warrant further research.

\section{Other nutritional perspectives related to enteric bacterial diseases}

Our review to date has focused on specific relationships between nutrition and some major enteric bacterial diseases of pigs. The following discussions expand on these general nutritional strategies and concepts and alert the reader to other nutritional approaches to controlling enteric disease.

\section{Minerals and polymers to control enteric diseases}

Zinc. $\mathrm{Zn}$ is a component of many metalloenzymes, including DNA and RNA synthetases and transferases, many digestive enzymes, and is associated with insulin; as such, it plays a crucial role in lipid, protein and carbohydrate metabolism in the pig. $\mathrm{Zn}$ is an essential element for pigs, and the National Research Council (1998) recommended intake for weaner pigs is 100 $\mathrm{mg} / \mathrm{kg}$ feed DM. The National Research Council (1998) remarked that the bioavailabilities (defined as a percentage of a recognised standard, for example, $\mathrm{ZnSO}_{4} .7 \mathrm{H}_{2} \mathrm{O}=100 \%$, rather than the actual percentage absorbed or retained) of different $\mathrm{Zn}$ compounds is generally less than $50 \%$, with the bioavailability of $\mathrm{ZnO}$ ranging from 40 to $95 \%$ (National Research Council, 1998; Mavromichalis et al. 1999). Zn from organic complexes appears to be more available than that from $\mathrm{ZnO}$, and equivalent to $\mathrm{Zn}$ from $\mathrm{ZnSO}_{4}$ (Schell \& Kornegay, 1996; Swinkels et al. 1996).

Interest in the growth-promoting properties of $\mathrm{ZnO}$ came to light after a report by Poulsen (1989; cited by National Research Council, 1998), who showed increased weight gain and 
reduced post-weaning scours in pigs when the weaner diet was supplemented with a pharmacological level (3000 parts per million (ppm)) of $\mathrm{ZnO}$ for $14 \mathrm{~d}$ after weaning. Numerous studies (reviewed by National Research Council, 1998; also Bertol \& Debrito, 1998; Carlson et al. 1999; Mavromichalis et al. 1999) have confirmed this earlier work, and now it is relatively commonplace to include $\mathrm{ZnO}$, at levels ranging anywhere between 2000 and $6000 \mathrm{ppm}$, in weanling pig diets. However, some other studies (see National Research Council, 1998; Windisch et al. 1998) have failed to show an improvement in performance with the use of $\mathrm{ZnO}$.

The growth-promotion attributes of $\mathrm{ZnO}$ might in part be due to its effectiveness in controlling PWC (for example, Holm, 1988; Poulsen, 1989; Bertol \& Debrito, 1998). With a ban on growth-promoting antibiotics in some countries, the reliance on pharmacological levels of $\mathrm{ZnO}$ in weaner diets to control enteric disease, particularly PWC, has increased. Despite its widespread use after weaning, the precise mechanism(s) whereby $\mathrm{ZnO}$ exerts its effects is uncertain. Huang et al. (1999) offered some insight into this question since pigs fed high doses of $\mathrm{ZnO}$ showed reduced bacterial translocation from the small intestine to ileal mesenteric lymph nodes. Other workers (for example, Carlson et al. 1999) suggested that high levels of ZnO induced metallothionein in gut enterocytes that, in turn, was involved in up regulation of RNA and DNA cell proliferation. Mavromichalis et al. (1999) found no improvement in gut structure due to addition of different sources of $\mathrm{ZnO}$. Other workers have not observed differences in diarrhoea, although changes in the microbial ecology appeared to occur with the use of $\mathrm{ZnO}$.

Jensen-Waern et al. (1997) reported that supplementation of a weaner diet with $2500 \mathrm{ppm}$ $\mathrm{ZnO}$ improved performance in pigs over a $28 \mathrm{~d}$ period following weaning, with no pigs showing any clinical signs of illness. However, this also occurred in the control group that did not receive $2500 \mathrm{ppm} \mathrm{ZnO}$. Use of $\mathrm{ZnO}$ had no effects on numbers of excreted E. coli or Enterococci spp./g of faeces, although these authors suggested that $\mathrm{ZnO}$ at growth-promoting levels in the diet might reduce the diversity within the gut microflora that, in turn, promotes a more stable ecology. In turn, Katouli et al. (1999) reported that addition of $2500 \mathrm{ppm} \mathrm{ZnO}$ to a weaner diet did not reduce total coliform numbers in the faeces, but control pigs showed an increase in both the variety and diversity of coliforms compared with pigs fed $\mathrm{ZnO}$. These authors recommended that $\mathrm{ZnO}$ be fed not longer than the first $14 \mathrm{~d}$ after weaning.

A major concern with the increasing use of pharmacological (growth-promoting) levels of $\mathrm{ZnO}$ is excretion of this mineral into the environment, with possible antibacterial effects on beneficial soil and water bacteria. Some countries, such as Denmark, are restricting ZnO levels in diets to reduce the amount of $\mathrm{Zn}$ leaving the pig and entering the environment. Although other forms of $\mathrm{Zn}$ such as zinc chelates and organic complexes have higher bioavailabilities than $\mathrm{ZnO}$, it is not known whether they are as effective in preventing enteric disease after weaning as $\mathrm{ZnO}$. Evidence in the literature to support their use is lacking, and they tend to be more expensive. The extent of diarrhoea after weaning obviously depends on a multitude of factors and conditions, and these will influence the effectiveness of any $\mathrm{Zn}$ compound relative to $\mathrm{ZnO}$. However, it would appear necessary to investigate alternative forms of $\mathrm{Zn}$ (or $\mathrm{ZnO}$ ) that not only have higher bioavailabilities (leading to reduced faecal excretion), but also have growth-promoting properties and ameliorate or prevent diarrhoea. Mavromichalis et al. (1999) compared two sources of $\mathrm{ZnO}$ that differed in their relative bioavailability (39v. $93 \%$ ) in weanling pigs, and reported no major differences between the two sources in their growth-promoting properties. No data were reported on the incidence of diarrhoea.

Copper. The pig needs $\mathrm{Cu}$ for the synthesis of haemoglobin and for the synthesis and activation of several oxidative enzymes necessary for normal metabolism. The National Research 
Council (1998) recommends a level of $6 \mathrm{mg} / \mathrm{kg}$ feed DM for weanling pigs. Cu salts with high biological availabilities include the sulfate, carbonate and chloride salts (Cromwell et al. 1998). Organic complexes of $\mathrm{Cu}$ appear to have equal bioavailability to $\mathrm{CuSO}_{4}$ (see National Research Council, 1998), although Coffey et al. (1994) reported that pigs fed a copper-lysine compound had a faster growth rate than pigs fed $\mathrm{CuSO}_{4}$, suggesting a difference in bioavailability and/or systemic effects. Coffey et al. (1994) also reported that $100 \mathrm{ppm} \mathrm{Cu}$ was as efficacious in stimulating growth as $200 \mathrm{ppm} \mathrm{Cu}$.

Braude (1945) was the first to show a growth response to high dietary $\mathrm{Cu}$ concentrations fed to growing-finishing pigs. When fed at $100-250 \mathrm{ppm}, \mathrm{Cu}\left(\mathrm{as}_{\mathrm{CuSO}}\right)$ has a growth-promoting effect in weanling pigs that appears to be independent of, but in addition to, the growth response elicited by antimicrobial compounds (National Research Council, 1998). In addition, the growth response to high levels of $\mathrm{CuSO}_{4}$ is increased by added fat, an effect attributed to enhanced lipase and phospholipase A activities (for example, Luo \& Dove, 1996). As with pharmacological levels of $\mathrm{ZnO}$, the precise mechanism(s) whereby $\mathrm{CuSO}_{4}$ exerts growth-promoting properties is (are) unknown, although some evidence suggests that it may have a systemic component (Zhou et al. 1994), in addition to any direct effect(s) in the gastrointestinal tract.

Interactions between other minerals, such as growth-promoting inclusion levels of $\mathrm{ZnO}$ in weanling pig diets, also require consideration. Recently, Hill et al. (2000) reported the results from twelve experimental stations in the USA investigating the effects of $\mathrm{Zn}$ and $\mathrm{Cu}$ supplementation above National Research Council (1998) requirements for weanling pigs $(6.55 \mathrm{~kg}$, weaned at $22 \mathrm{~d}$ of age). All diets contained chlortetracycline $(220 \mathrm{ppm})$ and were fed for $28 \mathrm{~d}$. Treatments were as follows: (a) control; (b) $3000 \mathrm{ppm} \mathrm{ZnO;} \mathrm{(c)} 250 \mathrm{ppm} \mathrm{CuSO}_{4}$; (d) $3000 \mathrm{ppm}$ $\mathrm{ZnO}$ plus $250 \mathrm{ppm} \mathrm{CuSO}$. Pharmacological levels of $\mathrm{ZnO}$ and $\mathrm{CuSO}_{4}$ enhanced growth rate and feed intake, and improved feed efficiency, beyond levels of $\mathrm{Zn}$ and $\mathrm{Cu}$ intake that met nutrient requirements. The combination of $\mathrm{Zn}$ and $\mathrm{Cu}$ did not cause an additive growth response. In another study, Hill et al. (2001) reported that supplemental $\mathrm{ZnO}$ at $1500-2000 \mathrm{ppm}$ plus an antibacterial agent (carbadox) improved post-weaning performance in an additive fashion.

Similar environmental pollution concerns to those expressed with regard to feeding high levels of $\mathrm{ZnO}$ have been raised with addition of growth-promoting levels of $\mathrm{CuSO}_{4}$ in diets, but $\mathrm{CuSO}_{4}$ may be more of an issue because it is often included in diets through the growing and finishing periods. Investigations into 'alternatives' to $\mathrm{CuSO}_{4}$ and $\mathrm{ZnO}$ require a focus on sources of minerals that are cost-effective, provide similar levels of control of enteric disease, and reduce the amount of mineral entering the environment.

Polymers. Work by Hampson et al. (2000) demonstrated that the use of a polymer (2-propenal, 2-propenoic acid, which is based on the polymerisation of 2-propenal) was effective in reducing colonisation and the incidence of diarrhoea of weaner piglets following both experimental challenge with E. coli and an on-farm trial. This product is thought to inactivate surface proteins on micro-organisms, thereby destroying them in a non-selective way.

\section{Influence of diet processing on enteric diseases}

A key influence on the physicochemical properties in vivo of ingested feed, especially cereals, is the type and extent of processing that the grain component undergoes before feeding. A multitude of changes occur in the chemistry of cereals (and perhaps oilseeds and legumes) during the various processing procedures, and these are relatively poorly understood. This is especially 
the case when trying to unravel factors responsible for maintenance of intestinal health, because it is likely that mechanical events occurring even before the pig eats its diet will have an impact on its capacity to digest and absorb the feed. Furthermore, these effects will also influence the microbial ecology of the gastrointestinal tract. The interactions that might exist between grain type and growing region, grain handling and processing, and the subsequent effects on the intestinal health of the pig require further investigation, particularly in relation to diseases such as salmonellosis and gastric ulceration.

Processing of grains breaks cell walls and reduces particle size. This is important because it determines the surface area that is exposed to the digestive and microbial enzymes, and influences the number of starch granules released from the protein-fibre matrix of the endosperm (Rowe et al. 1999). It has generally been considered that a 'fine' particle size is desirable because the surface area available for digestion will be increased. For example, Owsley et al. (1981) reported that ileal digestibility of starch in sorghum increased from $72 \%$ for dry rolled sorghum $(1.3 \mathrm{~mm}$ particle size) to $86 \%$ for hammer-milled sorghum passed through a $3.2 \mathrm{~mm}$ screen $(500 \mu \mathrm{m}$ particle size). However, comminuting grain too 'fine' may have adverse consequences for the prevalence of enteric diseases such as gastric ulceration, especially in wheatbased diets (pp. 355-356). Particle size is also important because, again depending on the cereal and even the cultivar within a cereal, it will largely determine the rate, extent and sites of digestion of starch within the gastrointestinal tract of the pig.

While the combination of enzymic activity in the small intestine and a (relatively) high fermentative activity in the hindgut results in a consistently high value for digestible energy content of grains, the pattern of digestion along the gastrointestinal tract may not necessarily be optimum with regard to nutrient absorption and utilisation, and hence the net energy content of a grain. The literature indicates that while there are well-established methods of processing grains to reduce particle size and achieve efficient digestion across the entire gastrointestinal tract (Rowe et al. 1999), information pertaining to the effects of processing and grain type on the rate, extent and site of digestion within specific regions of the gastrointestinal tract of the pig is less common. Furthermore, an undesirable pattern of digestion in the gastrointestinal tract might have dire consequences for the proliferation of certain bacteria that cause disease in pigs, such as in PIS and possibly PWC.

\section{Acid-binding capacity of feedstuffs and post-weaning colibacillosis}

Aumaitre et al. (1995) suggested that the activities of endogenous proteases are reduced in the post-weaning period by the presence of certain protein-containing feedstuffs, but not others. These included fishmeal or fish protein concentrate, by-products of the slaughter industry (for example, meat and bone meal), and the presence of 'high' amounts of soyabean meal in the diet. Animal protein products such as fishmeal and dried milk powders have high acid-binding capacity values (Bolduan et al. 1988). These feedstuffs bind more $\mathrm{HCl}$ in the stomach than cereals resulting in a higher $\mathrm{pH}$ (reduced acidity) and reduced pepsinogen production. As a consequence, proteolysis in the stomach might be diminished and the presence of 'extra' protein in the small intestine might overwhelm the digestive capacity of pancreatic and brush-border proteases in the upper regions of the small intestine, themselves relatively immature in the immediate post-weaning period. More protein would then move distally and be available for fermentation that, in turn, might predispose the young weaned pig to PWC. In addition, acidbinding capacity in the stomach might allow increased survival of pathogenic E. coli that is subject to faecal-oral recycling. In this regard there is considerable (re)interest in the use of 
organic acids as a means of lowering gastric $\mathrm{pH}$ that, in turn, might be associated with reduced proliferation of $E$. coli in the upper small intestine.

\section{Organic acids}

For a number of years organic acids have been used with varying success for amelioration of enteric infections. The withdrawal of growth-promoting antimicrobials has forced them back into focus as an alternative or replacement to antimicrobials in pig production. Several recent reviews (Partanen \& Mroz, 1999; Partanen, 2001) describe the rationale behind the use of organic acids and present results on digestibility of nutrients and their effects on some bacterial diseases (see Partanen, 2001). In the review by Partanen (2001), a meta-analysis of published data in weaned pigs revealed that improvements in production attributable to organic acids were observed due to an increase in voluntary food intake, although the exact mechanism(s) causing this effect are somewhat difficult to ascribe. This is no surprise given the multitude of factors affecting feed intake after weaning. The situation becomes complicated because different acids cause different effects, and studies have used different diets and conditions of hygiene that might also contribute to the differences observed. Furthermore, data associating the use of organic acids with reductions in diarrhoea are equivocal and data in vivo demonstrating that organic acids exert their effects by lowering gastric pH are lacking (Gabert \& Sauer, 1994; Partanen \& Mroz, 1999). Findings are also equivocal as to whether organic acids exert their effects by influencing dietary buffering capacity (Roth \& Kirchgessner, 1989).

In addition, Partanen (2001) commented that: 'It seems that the growth promoting effect of organic acids is primarily associated with effects on gastrointestinal microflora'. There are few data to support this notion, although some studies in both weaner and growing-finishing pigs (Øverland et al. 1999; 2000a,b; Canibe et al. 2001) have reported decreases in measurements such as total coliform counts and total anaerobic bacteria counts with the use of some acids (potassium diformate in this case). Partanen (2001) commented that organic acids not only act on pathogenic bacteria, but also modify beneficial flora, and considered that reduced microbial fermentation allows the pig increased access to the carbohydrates, which in turn improves performance. Considerable work is still needed in this area, particularly in the field of microbiological changes that occur in response to organic acids. It is possible also that other alternatives to in-feed antibiotics, such as enzymes (Partridge \& Tucker, 2000), might work in conjunction with organic acids to enhance performance after weaning. Regardless, work from the field in countries such as Sweden and Denmark suggests that certain organic acids have a positive effect on reducing the incidence of diseases such as PWC and salmonellosis, and hence are used widely in commercial practice.

\section{Nutraceuticals, botanicals and fatty acids}

There has been considerable interest in the use of these compounds to replace growth-promoting antimicrobials in diets for pigs. Although the scientific rationale and mechanisms behind the antimicrobial properties of these compounds to control enteric infections are not new, and in principle are sound, there are very few scientific data in vivo to support their efficacy in controlling enteric bacterial diseases.

A number of papers show marked in vitro effects of essential plant oils and extracts on a number of bacterial genera and species (for example, Hammer et al. 1999). Duncan et al. 
(1998) identified several specific metabolites isolated from plants, such as the coumarins esculetin, umbelliferone and scopoletin, which created inhibitory conditions in vitro for pathogens such as E. coli O157. These authors could not ascertain the exact mechanism(s) whereby the coumarins exerted their effects, though the results appear promising. Nevertheless, the majority of studies investigating nutraceuticals or botanicals have been conducted in vitro, and hence validation of these findings in vivo is still required.

It is recognised that compounds such as these possess potent anti-inflammatory and immunological actions. Recently, Bassaganya-Riera et al. (2001a,b) showed that conjugated linoleic acid enhanced cellular immunity in pigs by modulating phenotype and effector functions of CD8(+) cells involved in both adaptive and innate immunity. This occurred irrespective of whether pigs were in a 'clean' or 'dirty' environment. Development of cell-mediated immunity against pathogens in both the gut and the circulation are key defence mechanisms, and it might be possible to influence the development and duration of some enteric diseases by the addition of compounds such as conjugated linoleic acid.

\section{Exclusion products and probiosis}

Many of the successful enteric organisms have developed strategies to resist displacement from the epithelium via the development of anchoring adhesive fimbriae (pili). Approaches to masking these attachment sites from pathogenic bacteria include the feeding of certain lectins or competing carbohydrates (oligosaccharides) that inhibit attachment of certain bacteria to the epithelium (Kelly et al. 1994), to the provision of (avian) egg immunoglobulin G immunised against enterotoxigenic strains of E. coli (Mroz et al. 1999). For example, addition of $2.5 \%$ D-mannose to broiler diets reduced the excretion and colonisation of Salmonella enterica var. Typhimurium (Oyofo et al. 1988), while the use of a mannan oligosaccharide has been reported to reduce the concentration of caecal coliforms and Salmonella enterica var. Typhimurium and Salmonella Dublin in chicks (Spring et al. 2000). Similar studies in pigs have not been published in peer-reviewed journals.

McCracken \& Gaskins (1999) commented that dietary supplementation of human subjects and animals with probiotics has been shown to provide protection against intestinal, diarrhoeaproducing pathogens under certain situations, for example in 'dirty' facilities. Simpson et al. (2000) reported that the introduction of Lactobacillus reuteri strain MM53 to $21 \mathrm{~d}$ old piglets caused bacterial changes in the faeces that could be reliably assessed using denaturant gradient gel electrophoresis methodology. In 'clean' conditions though, the use of probiotics based on Lactobacillus spp. and Enterococcus spp. may in fact cause growth depression and deterioration in gut health because of the production of toxic metabolites (Gaskins, 2001). It would appear that the growth-promoting effects of probiotics in pigs are less consistent and quantifiably less evident than the use of antimicrobial compounds, although the recent technical developments in molecular microbiology have identified other probiotic strains that might have greater potential for enhancing disease resistance (Kelly, 1998).

\section{Conclusions}

This purpose of the present review was to describe the major enteric bacterial diseases of pigs in relation to where nutrition, in its broadest sense, has or might be used to prevent or modulate the incidence of disease. The restricted use and, in some parts of the world, the total ban on the 
use of antimicrobial agents, such as growth-promoting antibiotics and minerals, has resulted in a search for alternatives or replacements for these compounds in pig diets. This is particularly pertinent to the period following weaning, where diets have traditionally been fortified with antimicrobial agents to control the proliferation of diseases such as PWC. Data from countries such as Denmark (Hansen, 2000) and Sweden (Commission on Antimicrobial Feed Additives, 1997) suggest that banning and/or restricting the use of antimicrobial agents increases the incidence of clinical disease, increases mortality, reduces growth rates and increases the overall cost of production to slaughter weight. In these instances the use of 'nutrition' to compensate, at least in part, for the loss of antimicrobial agents has been adopted. Unfortunately, the underlying basis for many of the reported positive effects of nutrition on controlling enteric infections is poorly understood, so firm dietary recommendations to prevent or reduce clinical enteric disease cannot be made with full confidence. A greater understanding of how nutrition influences the intestinal environment, gut epithelial biology and immunobiology, and their interactions with both commensal and pathogenic bacteria, holds promise as a means of tackling enteric disease without antimicrobial agents. An important first step in defining the bacterial diversity of the gut was achieved recently by Leser et al. (2002), who compiled a library of 4270 cloned $16 \mathrm{~S}$ rDNA sequences representing 375 phylotypes from the ileum, caecum or the colon of pigs aged 12-18 weeks. In addition, it is important to consider the overall system of pig production in the context of controlling enteric bacterial diseases. In this regard, Penny (2000) commented that the pig industry, especially in Europe, needed to consider new management techniques plus a re-evaluation of existing production systems (for example, weaning age, bedding systems, allin, all-out management) to tackle this issue. In this regard, a postal survey by Pearce (1999a) found a negative association between the use of wet feeding systems and colitis in finishing pigs in a sample of UK pig herds. Although the statistical association between units adopting wet feeding and increased colitis does not necessarily indicate a causal relationship, it does highlight the overall complexity when faced with responding to enteric diseases. It is envisaged that this challenge will become greater if there is a total ban placed on all antimicrobial agents.

\section{Acknowledgements}

The Australian Research Council, Finnfeeds International Limited, and the Pig Research and Development Corporation of Australia have supported various aspects of the research described in this review. Acknowledgement is also expressed to our colleagues at Murdoch University and the Western Australian Department of Agriculture, particularly Dr Bruce Mullan, for their involvement and assistance in this work.

\section{References}

Accioly JM, Durmic Z, McDonald DE, Oxberry SL, Pethick DW, Mullan BP \& Hampson DJ (1998) Dietary effects on the presence of ulcers and urease-producing organisms in the stomach of weaner pigs. In Proceedings of the 15th International Pig Veterinary Society Congress, 3, p. 242. Birmingham, England: IPUS Committee.

Allison MJ, Robinson IM, Bucklin JA \& Booth GD (1979) Comparison of bacterial populations in the pig cecum and colon based upon enumeration with specific energy sources. Applied and Environmental Microbiology 37, 1142-1151.

Anderson, RC, Buckley SA, Callaway TR, Genovese KJ, Kubena LF, Harvey RB \& Nisbet DJ (2001) Effect of sodium chlorate on Salmonella sv. typhimurium concentrations in the pig gut. In Proceedings of the 8th Symposium on Digestive Physiology in Pigs, pp. 308-310 [J-E Lindberg and B Ogle, editors]. Wallingford: CABI Publishing.

Ange KD, Eisemann JH, Argenzio RA, Almond GW \& Blikslager AT (2000) Effects of feed physical form and buffering solutes on water disappearance and proximal stomach pH in swine. Journal of Animal Science 78, $2344-2352$. 
Annison G \& Topping D (1994) Nutritional role of resistant starch: chemical structure versus physiological function. Annual Reviews in Nutrition 14, 297-320.

Argenzio RA (1992) Pathophysiology of diarrhea. In Veterinary Gastroenterology, pp. 163-172 [N Anderson, editor]. Philadelphia: Lea and Fabiger.

Armstrong WD \& Cline TR (1976) Effects of various dietary nutrient levels on the incidence of colibacillary diarrhea in pigs: Intestinal ligation studies. Journal of Animal Science 42, 592-598.

Aumaitre A, Peiniau J \& Madec F (1995) Digestive adaptation after weaning and nutritional consequences in the piglet. Pig News and Information 16, 73N-79N.

Austin SC, Wiseman J \& Chesson A (1999) Influence of non-starch polysaccharides structure on the metabolisable energy of U.K. wheat fed to poultry. Journal of Cereal Science 29, 77-88.

Ayles HL, Friendship RM \& Ball RO (1996) Effect of dietary particle size on gastric ulcers, assessed by endoscopic examination, and relationships between ulcer severity and growth performance of individually fed pigs. Swine Health and Production 4, 211-216.

Bach Knudsen KE (1997) Carbohydrate and lignin contents of plant materials used in animal feeding. Animal Feed Science and Technology 67, 319-338.

Baghurst PA, Baghurst KI \& Record SJ (1996) Dietary fibre, non-starch polysaccharides and resistant starch: A review. Food Australia 48, S1-S35.

Ball RO \& Aherne FX (1982) Effect of diet complexity and feed restriction on the incidence and severity of diarrhoea in early weaned pigs. Canadian Journal of Animal Science 62, 907-913.

Barbosa AJA, Silva JCP, Nogueira AMMF, Paulino EJR \& Miranda CR (1995) Higher incidence of Gastrospirillium sp. in swine with gastric ulcers of the pars oesophagea. Veterinary Pathology 32, 134-139.

Barton MD (1999) The down-side of antibiotic use in pig production: The effect on antibiotic resistance of enteric bacteria. In Manipulating Pig Production VII, pp. 194-199 [PD Cranwell, editor]. Werribee: Australasian Pig Science Association.

Barton MD (2000) Antibiotic use in animal feed and its impact on human health. Nutrition Research Reviews 13,279-299.

Bassaganya-Riera J, Hontecillas Magarzo R, Bregendahl K, Wannemuehler MJ \& Zimmerman DR (2001a) Effects of dietary conjugated linoleic acid in nursery pigs of dirty and clean environments on growth, empty body composition, and immune competence. Journal of Animal Science 79, 714-721.

Bassaganya-Riera J, Hontecillas R, Zimmerman DR \& Wannemuehler MJ (2001b) Dietary conjugated linoleic acid modulates phenotype and effector functions of porcine cd8(+) lymphocytes. Journal of Nutrition 131, 2370-2377.

Beal JD, Moran CA, Campbell A \& Brooks PH (2001) The survival of potentially pathogenic E. coli in fermented liquid feed. In Proceedings of the 8th Symposium on Digestive Physiology in Pigs, pp. 351-353 [J-E Lindberg and B Ogle, editors]. Wallingford: CABI Publishing.

Bedford MR \& Apajalahti A (2001) Microbial interactions in the response to exogenous enzyme utilization. In Enzymes in Farm Animal Nutrition, pp. 299-314 [MR Bedford and GG Partridge, editors]. New York: CABI Publishing.

Belley A, Keller M, Goettke M \& Chadee K (1999) Intestinal mucins in colonization and host defense against pathogens. American Journal of Tropical Medicine and Hygiene 60, 10-19.

Bertol TM \& Debrito BG (1998) Effect of high levels of supplemental zinc on piglets' performance and mortality. Pesquisa Agropecuaria Brasileiri 33, 1493-1501.

Bertschinger HU (1999) Postweaning Escherichia coli diarrhea and edema disease. In Diseases of Swine, 8th ed., pp. 441-454 [BE Straw, S D’Allaire, WL Mengeling and DJ Taylor, editors]. Oxford: Blackwell Science.

Bertschinger HU, Eggenberger E, Jucker H \& Pfirter HP (1978) Evaluation of low nutrient, high fibre diets for the prevention of porcine Escherichia coli enterotoxaemia. Veterinary Microbiology 3, 281-290.

Bertschinger HU, Jucker H \& Pfirter HP (1979) Control of Escherichia coli infection in weaned pigs by use of oral immunization combined with a diet low in nutrients. Fortschriffe Veterinaria Medicine 29, 73-81.

Bolduan G, Jung H, Schnable E \& Schneider R (1988). Recent advances in the nutrition of weaner piglets. Pig News and Information $\mathbf{9}, 381-385$.

Braude R (1945) Some observations on the need for copper in the diet of fattening pigs. Journal of Agricultural Science 35, 163-171.

Brooks PH, Beal JD \& Niven S (2001) Liquid feeding of pigs: potential for reducing environmental impact and for improving productivity and food safety. In Recent Advances in Animal Nutrition in Australia 2001, pp. 49-64 [JL Corbett, editor]. Armidale: Animal Science, The University of New England.

Brooks PH, Geary TM, Morgan DT \& Campbell A (1996) New developments in liquid feeding. Pig Journal 36, 43-63.

Brunsgaard, G (1998) Effects of cereal type and feed particle size on morphological characteristics, epithelial cell proliferation, and lectin binding patterns in the large intestine of pigs. Journal of Animal Science 76, 2787-2798.

Canibe N, Steien SH, Overland M \& Jensen BB (2001) Effect of K-diformate in starter diets on acidity, microbiota and the amount of organic acids in th digestive tract of piglets, and on gastric alterations. Journal of Animal Science 79, 2123-2133.

Carlson MS, Hill GM \& Link JE (1999) Early- and traditionally weaned nursery pigs benefit from phase-feeding pharmacological concentrations of zinc oxide: Effect on metallothionein and mineral concentrations. Journal of Animal Science 77, 1199-1207.

Chandler DS \& Mynott TL (1998) Bromelain protects piglets from diarrhoea caused by oral challenge with K88 positive enterotoxigenic Escherichia coli. Gut 43, 196-202. 
Chang WL, Wu CF, Wu Y, Kao YM \& Pan MJ (1997) Prevalence of Lawsonia intracellularis in swine herds in Taiwan. Veterinary Record 141, 103-104.

Chesson A \& Stewart CS (2001) Modulation of the gut microflora by enzyme addition. In Gut Environment of Pigs, pp. 165-179 [A Piva, KE Bach Knudsen and J-E Lindberg, editors]. Loughborough: Nottingham University Press.

Choct M, Hughes RJ, Wang J, Bedford MR, Morgan AJ \& Annison G (1996) Increased small intestinal fermentation is partly responsible for the anti-nutritive activity of non-starch polysaccharides in chickens. British Poultry Science 37, 609-621.

Coffey RD, Cromwell GL \& Monegue HJ (1994) Efficacy of a copper-lysine complex as a growth promotant for weanling pigs. Journal of Animal Science 72, 2880-2886.

Commission on Antimicrobial Feed Additives (1997) Antimicrobial Feed Additives. Report from the Commission on Antimicrobial Feed Additives. Stockholm: Ministry of Agriculture.

Connor JF (1992) Nonspecific colitis. In Proceedings of the Australian Association of Pig Veterinarians, pp. 79-80. Adelaide, Australia: AVA.

Conway PL (1994) Function and regulation of the gastrointestinal microbiota of the pig. In Proceedings of the 6th International Symposium on Digestive Physiology in Pigs, EAAP Publication No. 80, pp. 231-240 [W-B Souffrant and H Hagemeister, editors]. Dummerstorf: Forschungsinstitut für die Biologie landwirtschaftlicher.

Cromwell GL, Lindemann ML, Monegue HJ, Hall DD \& Randolph JH (1998) Tribasic copper chloride and copper sulfate as copper sources for weanling pigs. Journal of Animal Science 76, 118-123.

Deplancke B \& Gaskins HR (2001) Microbial modulation of innate defense: Goblet cells and the intestinal mucus layer. American Journal of Clinical Nutrition 73, Suppl., 1131S-1141S.

Dréau D \& Lallès JP (1999) Contribution to the study of gut hypersensitivity reactions to soybean proteins in preruminant calves and early-weaned piglets. Livestock Production Science 60, 209-218.

Dubos RR, Schaedler RW, Costello R \& Hoet P (1965) Indigenous, normal and Autochthonous flora of the gastrointestinal tract. Journal of Experimental Medicine 122, 67-76.

Duncan SH, Flint HJ \& Stewart CS (1998) Inhibitory activity of gut bacteria against Escherichia coli O157 mediated by dietary plant metabolites. FEMS Microbiology Letters 164, 283-288.

Dunsford BR, Haensly WE \& Knabe DA (1991) Effects of diet on acidic and neutral goblet cell populations in the small intestine of early-weaned pigs. American Journal of Veterinary Research 52, 1743-1752.

Durmic Z, Pethick DW, Mullan BP, Schulze H, Accioly JM \& Hampson DJ (2000) Extrusion of wheat or sorghum and/or addition of exogenous enzymes to pig diets influences the large intestinal microbiota but does not prevent development of swine dysentery following experimental challenge. Journal of Applied Microbiology 89, 678-686.

Durmic Z, Pethick DW, Pluske JR \& Hampson DJ (1998) Influence of dietary fibre sources and levels of inclusion on the colonic microflora of pigs, and on the development of swine dysentery in experimentally-infected pigs. Journal of Applied Microbiology 85, 574-582.

Eisemann JH \& Argenzio RH (1999) Effects of diets differing in propensity to promote gastric lesions on defense systems in gastric mucosae. Journal of Animal Science 77, 2715-2720.

Etheridge RD, Seerley RW \& Wyatt RD (1984) The effect of diet on performance, digestibility, blood composition and intestinal microflora of weaned pigs. Journal of Animal Science 58, 1396-1402.

Fadel JG, Newman CW, Newman RK \& Graham H (1988) Effects of extrusion cooking of barley on ileal and fecal digestibilities of dietary components in pigs. Canadian Journal of Animal Science 68, 891-897.

Fernandez F, Sharma R, Hinton M \& Bedford MR (2000) Diet influences the colonisation of Campylobacter jejuni and distribution of mucin carbohydrates in the chick intestinal tract. Cellular and Molecular Life Sciences 57, 1793-1801.

Friendship RM (1999) Gastric ulcers. In Diseases of Swine, 8th ed., pp. 685-694 [BE Straw, WL Mengeling, S D’Allaire and DJ Taylor, editors]. Oxford: Blackwell Science Ltd.

Gabert VM \& Sauer WC (1994) The effects of supplementing diets for weanling pigs with organic acids. A review. Journal of Animal and Feed Sciences 3, 73-87.

Ganessunker D, Gaskins HR, Zuckermann FA \& Donovan SM (1999) Total parenteral nutrition alters molecular and cellular indices of intestinal inflammation in neonatal piglets. Journal of Parenteral and Enteral Nutrition, 23, $337-344$.

Gaskins HR (2001) Intestinal bacteria and their influence on swine growth. In Swine Nutrition, 2nd ed.,pp. 585-608 [AJ Lewis and LL Southern, editors]. Florida: CRC Press LLC.

Geary TM, Brooks PH, Beal JD \& Campbell A (1999) Effect on weaner pig performance and diet microbiology of feeding a liquid diet acidified to $\mathrm{pH} 4$ with either lactic acid or through fermentation with Pediococcus acidilactici. Journal of the Science of Food and Agriculture 79, 633-640.

Gibson GR \& Roberfroid MB (1995) Dietary modulation of the human colonic microbiota: introducing the concept of prebiotics. Journal of Nutrition 125, 1401-1412.

Hammer KA, Carson CF \& Riley TV (1999) Antimicrobial activity of essential oils and other plant extracts. Journal of Applied Microbiology 86, 985-990.

Hampson DJ (1987) Dietary influences on porcine postweaning diarrhoea. In Manipulating Pig Production, pp. 202-214 [JL Barnett, ES Batterham, GM Cronin, C Hansen, PH Hemsworth, PE Hughes, NE Johnston and RH King, editors]. Werribe: Australasian Pig Science Association.

Hampson DJ (1994) Postweaning Escherichia coli diarrhoea in pigs. In Escherichia coli in Domestic Animals and Humans, pp. 171-191 [CJ Gyles, editor]. Wallingford: CAB International. 
Hampson DJ, Cutler R \& Lee BJ (1992) Isolation of virulent Serpulina hyodysenteriae from a pig in a herd free of clinical swine dysentery. Veterinary Record 131, 318-319.

Hampson DJ, Hinton M \& Kidder DE (1985) Coliform numbers in the stomach and small intestine of healthy pigs following weaning at three weeks of age. Journal of Comparative Pathology 95, 353-362.

Hampson DJ, Phillips ND \& Pluske JR (2002) Dietary enzyme and zinc bacitracin reduce colonisation of layer hens by the intestinal spirochaete Brachyspira intermedia. Veterinary Microbiology 86, 351-360.

Hampson DJ, Pluske JR \& Pethick DW (2001) Dietary manipulation of enteric disease. In Proceedings of the VIIIth International Symposium on Digestive Physiology in Pigs, pp. 247-261 [J-E Lindberg and B Ogle, editors]. Wallingford: CAB International.

Hampson DJ, Robertson D, La T, Oxberry SL \& Pethick DW (2000) Influences of diet and vaccination on colonisation of pigs by the intestinal spirochaete Brachyspira (Serpulina) pilosicoli. Veterinary Microbiology 73, 75-84.

Hampson DJ \& Trott DJ (1995) Intestinal spirochaetal infections of pigs: An overview with an Australian perspective. In Manipulating Pig Production V, pp. 139-169 [DP Hennessy and PD Cranwell, editors]. Werribee: Australasian Pig Science Association.

Hampson DJ \& Trott DJ (1999) Spirochetal diarrhea/porcine intestinal spirochaetosis. In Diseases of Swine, 8th ed., pp. 553-562 [BE Straw, S D’Allaire, WL Mengeling and DJ Taylor, editors]. Oxford: Blackwell Science.

Hansen CF (2000) The role of Danske Slagterier in Danish pig production - focussing on cessation of using antibiotic growth promoters and on Salmonella. In Proceedings of the Society of Feed Technologists, pp. 111-114. Berkshire: Society of Feed Technologists.

Harris DL, Hampson DJ \& Glock RD (1999) Swine dysentery. In Diseases of Swine, 8th ed., pp. 579-600 [BE Straw, S D'Allaire, WL Mengeling and DJ Taylor, editors]. Oxford: Blackwell Science.

Harris IT, Fedorka-Cray PJ, Gray JT, Thomas LA \& Ferris K (1997) Prevalence of Salmonella organism in swine feed. Journal of the American Veterinary Medical Association 210, 382-385.

Healy BJ, Hancock JD, Kennedy GA, Bramelcox PJ, Behnke KC \& Hines RH (1994) Optimum particle size of corn and hard and soft sorghum for nursery pigs. Journal of Animal Science 72, 2227-2236.

Hill GM, Cromwell GL, Crenshaw TD, Dove CR, Ewan RC, Knabe DA, Lewis AJ, Libal GW, Mahan DC, Shurson GC, Southern LL \& Veum TL (2000) Growth promotion effects and plasma changes from feeding high dietary concentrations of zinc and copper to weanling pigs (regional study). Journal of Animal Science 78, 1010-1016.

Hill GM, Mahan DC, Carter SD, Cromwell GL, Ewan RC, Harrold RL, Lewis AJ, Miller PS, Shurson GC \& Veum TL (2001) Effect of pharmacological concentrations of zinc oxide with or without the inclusion of an antibacterial agent on pig performance. Journal of Animal Science 79, 934-941.

Hillman K, Murdoch TA, Spencer RJ \& Stewart CS (1994) Inhibition of enterotoxigenic Escherichia coli by the microflora of the porcine ileum, in an in vitro semicontinuous culture system. Journal of Applied Microbiology 76, 294-300.

Hillman K, Spencer RJ, Murdoch TA \& Stewart CS (1995) The effect of mixtures of Lactobacillus spp. on the survival of enterotoxigenic Escherichia coli in in vitro continuous culture of porcine intestinal bacteria. Letters in Applied Microbiology 20, 130-133.

Holm A (1988) Escherichia coli associated diarrhoea in weaner pigs: Zinc oxide added to the feed as a preservative measure. Danske Veterinaerntidsskr 72,1118 Abstr.

Houdijk J (1998) Effects of non-digestible oligosaccharides in young pig diets. PhD Thesis, Wageningen Agricultural University.

Huang SX, McFall M, Cegielski AC \& Kirkwood RN (1999) Effect of dietary zinc supplementation on Escherichia coli septicemia in weaned pigs. Swine Health and Production 7, 109-111.

Inborr J \& Ogle RB (1988) Effect of enzyme treatment of piglet feeds on performance and post weaning diarrhoea. Swedish Journal of Agricultural Research 18, 129-133.

Jensen BB (1998) The impact of feed additives on the microbial ecology of the gut in young pigs. Journal of Animal and Feed Sciences 7, 45-64.

Jensen BB (2001) Possible ways of modifying type and amount of products from microbial fermentation in the gut. In Gut Environment of Pigs, pp. 181-200 [A Piva, KE Bach Knudsen and J-E Lindberg, editors]. Loughborough: Nottingham University Press.

Jensen BB \& Mikkelsen LL (1998) Feeding liquid diets to pigs. In Recent Advances in Animal Nutrition 1998 pp. 107-126 [PC Garnsworthy and J Wiseman, editors]. Nottingham: Nottingham University Press.

Jensen-Waern M, Melin L, Lindberg R, Johannisson A, Petersson L \& Wallgren P (1997) Dietary zinc oxide in weaned pigs - effects on performance, tissue concentrations, morphology, neutrophil functions and faecal microflora. Research in Veterinary Science 64, 225-231.

Johnston WT, Dewey CE, Friendship RM, Smart N, McEwan BJ, Stalker M \& Lange CFM (2001) An investigation of the etiology of a mild diarrhoea observed in a group of grower/finisher pigs. Canadian Veterinary Journal 42, 33-37.

Jones PH, Roe JM \& Miller BG (2001) Effects of stressors on immune parameters and on the faecal shedding of enterotoxigenic Escherichia coli in piglets following experimental inoculation. Research in Veterinary Science 70, 9-17.

Katouli M, Melin L, Jensen-Waern M, Wallgren P \& Mollby R (1999) The effect of zinc oxide supplementation on the stability of the intestinal flora with special reference to composition of coliforms in weaned pigs. Journal of Applied Microbiology 87, 564-573.

Kelly D (1998) Probiotics in young and newborn animals. Journal of Animal and Feed Sciences 7, Suppl. 1, 15-23. 
Kelly D, Begbie R \& King TP (1994) Nutritional influences on interactions between bacteria and the small intestinal mucosa. Nutrition Research Reviews 7, 233-257.

Kelly D \& King TP (2001) Luminal bacteria: Regulation of gut function and immunity. In Gut Environment of Pigs, pp. 113-131 [A Piva, KE Bach Knudsen and J-E Lindberg, editors]. Loughborough: Nottingham University Press.

Kennedy MJ, Rosnick DK, Ulrich RG \& Yancey RJ (1988) Association of Treponema hyodysenteriae with porcine intestinal mucosa. Journal of General Microbiology 134, 1565-1574.

Kenworthy R \& Crabb WE (1963) The intestinal flora of young pigs, with reference to early weaning, Escherichia coli and scours. Journal of Comparative Pathology 73, 215-228.

Kiers JL, Nout MJR, Rombouts FM, Nabuurs MJA \& van der Meulen J (2001) Protective effects of processed soybean during perfusion of ETEC-infected small intestinal segments of early-weaned piglets. In Proceedings of the 8th Symposium on Digestive Physiology in Pigs, pp. 261-263 [J-E Lindberg and B Ogle, editors]. Wallingford: CABI Publishing.

Kim O, Kim B \& Chae C (1998) Prevalence of Lawsonia intracellularis in selected pig herds in Korea as determined by PCR. Veterinary Record 143, 587-589.

King TP \& Kelly D (2001) Glycobiology, the microbiota and enteric health in young pigs. In Concepts in Pig Science 2001: Proceedings of the 3rd Annual Turtle Lake Pig Science Conference, pp. 157-176 [TP Lyons and DJA Cole, editors]. Nottingham: Nottingham University Press.

Kirkwood RN, Huang SX, McFall M \& Aherne FX (2000) Dietary factors do not influence the clinical expression of swine dysentery. Swine Health and Production 8, 73-76.

Knittel JP (1999) Porcine proliferative enteropathy and Lawsonia intracellularis. Compendium of Continuing Veterinary Practice 21, S53-S59.

Krakowka S, Eaton KA, Rings DM \& Argenzio RA (1998) Production of gastroesophageal erosions and ulcers (GEU) in gnotobiotic swine monoinfected with fermentative commensal bacteria and fed high-carbohydrate diet. Veterinary Pathology 35, 274-282.

Lang J, Blikslager D, Regina J, Eisemann J \& Argenzio R (1998) Synergistic effect of hydrochloric acid and bile acids on the pars esophageal mucosa of the porcine stomach. American Journal of Veterinary Research 59, 1170-1176.

Langhout DJ (1998) The role of the intestinal flora as affected by non-starch polysaccharides in broiler chicks. PhD Thesis, Wageningen Agricultural University.

Langhout DJ, Schutte JB, de Jong J, Sloetjes H, Vertsegen MWA \& Tamminga S (2000) Effect of viscosity on digestion of nutrients in conventional and germ-free chicks. British Journal of Nutrition 83, 533-540.

Lawrence BV, Anderson DB, Adeola O \& Cline TR (1998) Changes in pars esophageal tissue appearance of the porcine stomach in response to transportation, feed deprivation, and diet composition. Journal of Animal Science 76, 788-795.

Lecce JG, Clare DA, Balsbaugh RK \& Collier DN (1983) Effects of dietary regimen on rotavirus-Escherichia coli weanling diarrhoea of piglets. Journal of Clinical Microbiology 17, 689-695.

Leser TD, Amenuvor JZ, Jensen TK, Lindecrona RH, Boye M \& Møller K (2002) Culture-independent analysis of gut bacteria: The pig gastrointestinal tract microbiota revisited. Applied and Environmental Microbiology 68, 673-690.

Leser TD, Lindecrona RH, Jensen TK, Jensen BB \& Møller K (2000) Changes in bacterial community structure in the colon of pigs fed different experimental diets and after infection with Brachyspira hyodysenteriae. Applied and Environmental Microbiology 66, 3290-3296.

Li S, Sauer WC \& Fan MZ (1993) The effect of dietary crude protein level on ileal and faecal amino acid digestibility in early-weaned pigs. Journal of Animal Physiology and Nutrition 70, 117-128.

Luo XG \& Dove CR (1996) Effect of dietary copper and fat on nutrient utilization, digestive enzyme activities, and tissue mineral levels in weanling pigs. Journal of Animal Science 74, 1888-1896.

McCracken BA \& Gaskins HR (1999) Intestinal microbes and the immune system. In Probiotics: A Critical Review, pp. 85-109 [GW Tannock, editor]. Norfolk: Horizon Scientific Press.

McDonald DE (2001) Dietary fibre for the newly weaned pig: Influences on pig performance, intestinal development and expression of experimental post-weaning colibacillosis and intestinal spirochaetosis. PhD Thesis, Murdoch University, Perth.

McDonald DE, Pethick DW, Mullan BP \& Hampson DJ (2001a) Increasing viscosity of the intestinal contents alters small intestinal structure and intestinal growth, and stimulates proliferation of enterotoxigenic Escherichia coli in newly weaned pigs. British Journal of Nutrition 86, 487-498.

McDonald DE, Pethick DW, Mullan BP, Pluske JR \& Hampson DJ (2001b) Soluble non-starch polysaccharides from pearl barley exacerbate experimental post-weaning colibacillosis. In Proceedings of the 8th Symposium on Digestive Physiology in Pigs, pp. 280-282 [J-E Lindberg and B Ogle, editors]. Wallingford: CABI Publishing.

McDonald DE, Pethick DW, Pluske JR \& Hampson DJ (1999) Adverse effects of soluble non-starch polysaccharide (guar gum) on piglet growth and experimental colibacillosis immediately after weaning. Research in Veterinary Science 67, 245-250.

McOrist S \& Gebhart CJ (1999) Porcine proliferative enteropathies. In Diseases of Swine, 8th ed., pp. 521-534 [BE Straw, S D'Allaire, WL Mengeling and DJ Taylor, editors]. Oxford: Blackwell Science.

Mackie RI, Sghir A \& Gaskins HR (1999) Developmental microbial ecology of the neonatal gastrointestinal tract. American Journal of Clinical Nutrition 69, 1035S-1045S.

Madec F, Bridoux N, Bounaix S, Cariolet R, Duval-Iflah Y, Hampson DJ \& Jestin A (2000) Experimental models of porcine post-weaning colibacillosis and their relationship to post-weaning diarrhoea and digestive disorders as encountered in the field. Veterinary Microbiology 72, 295-310. 
Madec F, Bridoux N, Bounaix S \& Jestin A (1998) Measurement of digestive disorders in the piglet at weaning and related risk factors. Preventative Veterinary Medicine 35, 53-72.

Mathews CJ, MacLeod RJ, Zheng SX, Hanrahan JW, Bennett HP \& Hamilton JR (1999) Characterization of the inhibitory effect of boiled rice on intestinal chloride secretion in guinea pig crypt cells. Gastroenterology 116, 1342-1347.

Mavromichalis I, Hancock JD, Senne BW, Gugle TL, Kennedy GA, Hines RH \& Wyatt CL (2000) Enzyme supplementation and particle size of wheat in diets for nursery and finishing pigs. Journal of Animal Science 78, 3086-3095.

Mavromichalis I, Peter CM, Parr TM, Ganessunker D \& Baker DH (1999) Growth-promoting efficacy in young pigs of two sources of zinc oxide having either a high or low bioavailability of zinc. Journal of Animal Science 78, 2896-2902.

Meyer RC, Simon J \& Byerly CS (1975) The etiology of swine dysentery. III. The role of selected gram-negative obligate anaerobes. Veterinary Pathology 12, 46-54.

Mhoma JRL, Hampson DJ \& Robertson ID (1992) A serological survey to determine the prevalence of infection with Treponema hyodysenteriae in Western Australia. Australian Veterinary Journal 69, 81-84.

Mikkelsen LL \& Jensen BB (2000) Effect of fermented liquid feed on the activity and composition of the microbiota in the gut of pigs. Pig News and Information 21, 59N-66N.

Mikkelsen LL \& Jensen BB (2001) Bifidobacteria in piglets. In Proceedings of the 8th Symposium on Digestive Physiology in Pigs, pp. 285-288 [J-E Lindberg and B Ogle, editors]. Wallingford: CABI Publishing.

Miller BG, Newby TJ, Stokes CR \& Bourne FJ (1984) Influence of diet on post-weaning malabsorption and diarrhoea in the pig. Research in Veterinary Science 36, 187-193.

Møller K, Jensen TK, Jorsal SE, Leser TD \& Carstensen B (1998) Detection of Lawsonia intracellularis, Serpulina hyodysenteriae, weakly beta-haemolytic intestinal spirochaetes, Salmonella enterica, and haemolytic Escherichia coli from swine herds with and without diarrhoea among growing pigs. Veterinary Microbiology 62, 59-72.

Moore WEC, Moore LVH, Cato EP, Wilkins TD \& Kornegay ET (1987) Effect of high-fiber and high-oil diets on the fecal flora of swine. Applied and Environmental Microbiology 53, 1638-1644.

Moran CA, Ward G, Beal JD, Campbell A, Brooks PH \& Miller BG (2001) Influence of liquid feed, fermented liquid feed, dry feed and sow's milk fed ad libitum, on the 'ecophysiology' of the terminal ileum, caecum and colon of the postweaned pig. In Proceedings of the 8th Symposium on Digestive Physiology in Pigs, pp. 266-268 [J-E Lindberg and B Ogle, editors]. Wallingford: CABI Publishing.

Mroz Z, Grela ER, Matras J, Krasucki W, Kichura T \& Shipp TE (1999) Passive protection of piglets against diarrhoea with specialized egg immunoglobulins (Protimax). In Manipulating Pig Production VII, p. 238 [PD Cranwell, editor]. Werribee: Australasian Pig Science Association.

Mynott TL, Luke RKJ \& Chandler DS (1996) Oral administration of protease inhibits enterotoxigenic Escherichia coli receptor activity in piglet small intestine. Gut 38, 28-32.

National Research Council (1998) Nutrient Requirements of Swine. 10th revised ed. Washington, DC: National Research Council.

Nielsen EK \& Ingvartsen KL (2000a) Effect of cereal type, disintegration method and pelleting on stomach content, weight and ulcers and performance in growing pigs. Livestock Production Science 66, 271-282.

Nielsen EK \& Ingvartsen KL (2000b) Effect of cereal disintegration method, feeding method and straw as bedding on stomach characteristics including ulcers and performance in growing pigs. Acta Agriculturae Scandinavica 50A, 30-38.

Nollet H, Deprez P, Van Driessche E \& Muylle E (1999a) Protection of just weaned pigs against infection with F18(+) Escherichia coli by non-immune plasma powder. Veterinary Microbiology 65, 37-45.

Nollet H, Laevens H, Deprez P, Sanchez R, Van Driessole E \& Muylle E (1999b) The use of non-immune plasma powder in the prophylaxis of neonatal Escherichia coli diarrhoea. Zentralblatt fur Veterinarmedizin - Reihe A 46, $185-196$.

Nout MJ, Rombouts FM \& Havelaar A (1989) Effect of accelerated neutral lactic acid fermentation of infant food ingredients on some pathogenic microorganisms. International Journal of Food Microbiology 8, 351-361.

Øverland M, Granli T, Kjos NP, Fjetland O, Steien SH \& Stokstad M (2000a) Effect of dietary formates on growth performance, carcass traits, sensory quality, intestinal microflora, and stomach alterations in growing-finishing pigs. Journal of Animal Science 78, 1875-1884.

Øverland M, Mroz Z, Granli T \& Steien SH (2000b) Performance and mode of action of dietary potassium diformate for weanling pigs. In Proceedings of the European Association of Animal Production. Wageningen: Wageningen Pers.

Øverland M, Steien SH, Gotterbarm G \& Granli T (1999) K-diformate (Formi ${ }^{\text {TM}}$ LHS) in diets for pigs. In Manipulating Pig Production VII, p. 127 [PD Cranwell, editor]. Werribee: Australasian Pig Science Association.

Owsley WF, Knabe DA \& Tanksley TD (1981) Effect of sorghum particle size on digestibility of nutrients at the terminal ileum and over the total digestive tract of growing-finishing pigs. Journal of Animal Science 52, 557-566.

Oyofo BA, De Loach JR, Corrier DE, Norman JO, Ziprin RL \& Mollenhauer HH (1988) Prevention of Salmonella typhimurium colonization of broilers with D-mannose. Poultry Science 68, 1357-1360.

Pace NR (1997) A molecular view of microbial diversity and the biosphere. Science 276, 734.

Partanen, K. (2001) Organic acids - their efficacy and modes of action in pigs. In Gut Environment of Pigs, pp. 201-217 [A Piva, KE Bach Knudsen and J-E Lindberg, editors]. Loughborough: Nottingham University Press. 
Partanen K \& Mroz Z (1999) Organic acids for performance enhancement in pig diets. Nutrition Research Reviews 12 , $117-145$.

Partridge GG (1998) Enzyme's role in health. Feed Mix 6, 23-25.

Partridge GG (2001) The role and efficacy of carbohydrase enzymes in pig nutrition. In Enzymes in Farm Animal Nutrition, pp. 161-198 [MR Bedford and GG Partridge, editors]. Wallingford: CABI Publishing.

Partridge, GG \& Tucker L (2000) A healthy role for enzymes. Pig International 30, 28-31.

Pearce GP (1999a) Epidemiology of enteric disease in grower-finisher pigs: a postal survey of pig producers in England. Veterinary Record 144, 338-342.

Pearce GP (1999b) Interactions between dietary fibre, endo-parasites and Lawsonia intracellularis bacteria in growerfinisher pigs. Veterinary Parasitology 87, 51-61.

Penny P (2000) Management techniques as alternatives to growth promoters. In Proceedings of the Society of Feed Technologists, pp. 115-121. Reading, Berkshire: Society of Feed Technologists.

Pestova MI, Clift RE, Vickers RJ, Franklin MA \& Mathew AG (2000) Effect of weaning and dietary galactose supplementation on digesta glycoproteins in pigs. Journal of the Science of Food and Agriculture 80, 1918-1924.

Petkevicius S, Bach-Knudsen KE, Nansen P, Roepstorff A, Skjorth F \& Jensen F (1997) The impact of diets varying in carbohydrate resistance to endogenous enzymes and lignin on populations of Ascaris suum and Oesaphagastomum dentatum in pigs. Parasitology 114, 555-568.

Phadtare S, Alsina J \& Inouye M (1999) Cold-shock response and cold-shock proteins. Current Opinions in Microbiology 2, 175-180.

Pluske JR, Durmic Z, Pethick DW, Mullan BP \& Hampson DJ (1998) Confirmation of the role of rapidly fermentable carbohydrates in the expression of swine dysentery in pigs after experimental infection. Journal of Nutrition 128, 1737-1744.

Pluske JR, Kim JC, McDonald DE, Pethick DW \& Hampson DJ (2001) Non-starch polysaccharides in the diets of young weaned piglets. In The Weaner Pig, pp.81-112 [MA Varley and J Wiseman, editors]. Wallingford: CAB International.

Pluske JR, Siba PM, Pethick DW, Durmic Z, Mullan BP \& Hampson DJ (1996) The incidence of swine dysentery in pigs can be reduced by feeding diets that limit the amount of fermentable substrate entering the large intestine. Journal of Nutrition 126, 2920-2933.

Porter P \& Kenworthy R (1969) A study of intestinal and urinary amines in pigs in relation to weaning. Research in Veterinary Science 10, 440-447.

Poulsen HD (1989) Zinc oxide for pigs during weaning. Meddelelse no. 746. Denmark: Statens Husdrybrugsforsoeq.

Pouteaux VA, Christison GI \& Rhodes CS (1982) The involvement of dietary protein source and chilling in the etiology of diarrhoea in newly-weaned pigs. Canadian Journal of Animal Science 62, 1199-1209.

Prohászka L \& Baron F (1980) The predisposing role of high protein supplies in enteropathogenic Escherichia coli infections of weaned pigs. Zentralblatt für Veterinarmedizin B 27, 222-232.

Prohászka L \& Lukács K (1984) Influence of the diet on the antibacterial effect of volatile fatty acids and on the development of swine dysentery. Zentralblatt für Veterinarmedizin B 31, 779-785.

Pryde SE, Richardson AJ, Stewart CS \& Flint HJ (1999) Molecular analysis of the microbial diversity present in the colonic wall, colonic lumen, and cecal lumen of the pig. Applied and Environmental Microbiology 65, 5372-5377.

Queiroz DMM, Rocha GA, Mendes EN, Moura SB, Oliveira AMR \& Miranda D (1996) Association between Helicobacter and gastric ulcer disease on the pars oesophagea in swine. Gastroenterology 111, 19-27.

Rantzer D, Svendsen J \& Westrom B (1996) Effects of a strategic feed restriction on pig performance and health during the post-weaning period. Acta Agriculturae Scandinavica 46A, 219-226.

Reed WM, Olander HJ \& Thacker HL (1985) Studies on the pathogenesis of Salmonella heidelberg infection in weanling pigs. American Journal of Veterinary Research 46, 2300-2310.

Regina DC, Eisemann JH, Lang JA \& Argenzio RA (1999) Changes in gastric contents in pigs fed a finely ground and pelleted or coarsely ground meal diet. Journal of Animal Science 77, 2721-2729.

Reid C-A \& Hillman K (1999) The effects of retrogradation and amylose/amylopectin ratio of starches on carbohydrate fermentation and microbial populations in the porcine colon. Animal Science 68, 503-510.

Reid C-A, Hillman K \& Henderson C (1998) The effect of retrogradation, pancreatic digestion and amylose/amylopectin ratio on the fermentation of starch by Clostridium butyricum (NCIMB 7423). Journal of the Science of Food and Agriculture 76, 221-225.

Reid C-A, Hillman K, Henderson C \& Glass H (1996) Fermentation of native and processed starches by the porcine caecal anaerobe Clostridium butyricum (NCIMB 7423). Journal of Applied Microbiology 80, 191-198.

Robertson JA, Majsak-Newman G, Ring SG \& Selvendran RR (1997) Solubilisation of mixed linkage $(1 \rightarrow 3)$, $(1 \rightarrow 4)$ $\beta$-D-glucans from barley: Effects of cooking and digestion. Journal of Cereal Science 25, 275-283.

Robinson IM, Allison MJ \& Bucklin JA (1981) Characterization of the cecal bacteria of normal pigs. Applied and Environmental Microbiology, 41, 950-955.

Rossi F, Cox E, Goddeeris B, Portetelle D, Wavreille J \& Théwis A (2001) Inulin incorporation in the weaned pig diet: Intestinal coliform interaction and effect on specific systemic immunity. In Proceedings of the 8th Symposium on Digestive Physiology in Pigs, pp. 299-301 [J-E Lindberg and B Ogle, editors]. Wallingford: CABI Publishing.

Rossi S, Bonferoni MC, Ferrari F, Bertoni M \& Caramell C (1996) Characterization of mucin interaction with three viscosity grades of sodium carboxymethylcellulose. Comparison between rheological and tensile testing. European Journal of Pharmaceutical Sciences 4, 189-196. 
Roth FX \& Kirchgessner M (1989) Significance of dietary pH and buffering capacity in piglet nutrition. 1. pH and buffering capacity of diets supplemented with organic acids. Landwirtschaftliche Forschung 42, 157-167.

Rowe JB, Choct M \& Pethick DW (1999) Processing cereal grains for animal feeding. Australian Journal of Agricultural Research 50, 721-736.

Russell EG (1979) Types and distribution of anaerobic bacteria in the large intestine of pigs. Applied and Environmental Microbiology 37, 187-193.

Russell JB \& Diez-Gonzalez F (1998) The effects of fermentation acids on bacterial growth. Advances in Microbial Physiology 39, 205-214.

Salanitro JP, Blake IG \& Muirhead PA (1977) Isolation and identification of fecal bacteria from adult swine. Applied and Environmental Microbiology 33, 79-84.

Schell TC \& Kornegay ET (1996) Zinc concentrations in tissues and performance of weanling pigs fed pharmacological levels of zinc from $\mathrm{ZnO}, \mathrm{Zn}$-methionine, $\mathrm{Zn}$-lysine and $\mathrm{ZnSO}_{4}$. Journal of Animal Science 74, 1584-1593.

Schwartz KJ (1999) Salmonellosis. In Diseases of Swine, 8th ed., pp. 535-551 [BE Straw, S D'Allaire, WL Mengeling and DJ Taylor, editors]. Oxford: Blackwell Science.

Sharma R, Fernandez F, Hinton M \& Schumacher U (1997) The influence of diet on the mucin carbohydrates in the chick intestinal tract. Cellular and Molecular Life Sciences 534, 935-942.

Shimizu M \& Terashima T (1982) Appearance of enterotoxigenic Escherichia coli in piglets with diarrhoea in connection with feed changes. Microbiology and Immunology 26, 467-477.

Siba PB, Pethick DW \& Hampson DJ (1996) Pigs experimentally infected with Serpulina hyodysenteriae can be protected from developing swine dysentery by feeding them a highly digestible diet. Epidemiology and Infection 116, $207-216$.

Simpson JM, McCracken VJ, Gaskins HR \& Mackie RI (2000) Denaturing gradient gel electrophoresis analysis of 16s ribosomal DNA amplicons to monitor changes in fecal bacterial populations of weaning pigs after introduction of Lactobacillus reuteri strain MM53. Applied and Environmental Microbiology 66, 4705-4714.

Simpson JM, McCracken VJ, White BA, Gaskins HR \& Mackie RI (1999) Application of denaturant gradient gel electrophoresis for the analysis of the porcine gastrointestinal microbiota. Journal of Microbiological Methods 36, $167-179$.

Smith HW \& Halls S (1968) The production of oedema disease and diarrhoea in weaned pigs by the oral administration of Escherichia coli: factors that influence the course of the experimental disease. Journal of Medical Microbiology $\mathbf{1}$, 45-59.

Smith HW \& Jones JET (1963) Observations on the alimentary tract and its bacterial flora in healthy and diseased pigs. Journal of Pathology and Bacteriology 86, 387-412.

Smith WJ \& Nelson EP (1987) Grower scour/non-specific colitis. Veterinary Record 121, 334.

Smits CH, Veldman A, Verkade HJ \& Beynen AC (1998) The inhibitory effect of carboxymethylcellulose with high viscosity on lipid absorption in broiler chickens coincides with reduced bile salt concentration and raised microbial numbers in the small intestine. Poultry Science 77, 1534-1539.

Spring P, Wenk C, Dawson KA \& Newman KE (2000) The effects of dietary mannanoligosaccharides on cecal parameters and the concentrations of enteric bacteria in the ceca of Salmonella-challenged broiler chicks. Poultry Science 79, 205-211.

Steer T, Carpenter H, Tuohy K \& Gibson GR (2000) Perspectives on the role of the human gut microbiota and its modulation by pro- and prebiotics. Nutrition Research Reviews 13, 229-254.

Stege H, Dahl J, Christensen J, Baggesen DL, Nielsen JP \& Willeberg P (1997) Subclinical Salmonella infections in Danish finishing pig herds: Risk factors. In Proceedings of the 2nd International Symposium on the Epidemiology and Control of Salmonella in Pork, pp. 148-152. Copenhagen: University of Copenhagen.

Stege H, Jensen TK, Moller K, Baekbo P \& Jorsal SE (2000) Prevalence of intestinal pathogens in Danish finishing pig herds. Preventative Veterinary Medicine 46, 279-292.

Stege H, Jensen TK, Moller K, Baekbo P \& Jorsal SE (2001) Risk factors for intestinal pathogens in Danish finishing pig herds. Preventative Veterinary Medicine 50, 153-164.

Stewart CS (1997) Microorganisms in hindgut fermenters. In Gastrointestinal Microbiology, pp. 142-186 [RI Mackie, BA White and RE Isaacson, editors]. New York: Chapman and Hall.

Stokes CR, Bailey M \& Haverson K (2001) Development and function of the pig gastrointestinal immune system. In Proceedings of the 8th Symposium on Digestive Physiology in Pigs, pp. 59-66 [J-E Lindberg and B Ogle, editors]. Wallingford: CABI Publishing.

Swinkels JWGM, Kornegay ET, Zhou W, Lindemann MD, Webb KE Jr \& Verstegen MWA (1996) Effectiveness of a zinc amino acid chelate and zinc sulfate in restoring serum and soft tissue zinc concentrations when fed to zincdepleted pigs. Journal of Animal Science 74, 2420-2430.

Tannock GW (1999) A fresh look at the intestinal microflora. In Probiotics: A Critical Review, pp. 5-14 [GW Tannock, editor]. Norfolk: Horizon Scientific Press.

Thomson JR, Smith WJ \& Murray BP (1998) Investigations into field cases of porcine colitis with particular reference to infection with Serpulina pilosicoli. Veterinary Record 142, 235-239.

Trott DJ, Stanton TB, Jensen NS, Duhamel GE, Johnson J \& Hampson DJ (1996) Serpulina pilosicoli sp. nov., the agent of porcine intestinal spirochaetosis. International Journal of Systemic Bacteriology 46, 206-215.

van der Wolf PJ, Bongers JH, Elbers ARW, Franssen FMMC, Hunneman WA, Van Exsel AC \& Tielen MJM (1999) Salmonella infections in finishing pigs in The Netherlands: bacteriological herd prevalence, serogroup and antibiotic resistance of isolates and risk factors for infection. Veterinary Microbiology 67, 263-275. 
Van Winsen RL, Urlings BAP, Lipmanm LJA, Snijders JMA, Keuzenkamp D, Verjeijden JHM \& van Knapen F (2001) Effect of fermented feed on the microbial population of the gastrointestinal tracts of pigs. Applied and Environmental Microbiology 67, 3071-3076.

Wathes CM, Miller BG \& Bourne FJ (1989) Cold stress and post-weaning diarrhoea in piglets inoculated orally or by aerosol. Animal Production 49, 483-496.

Whipp SC, Robinson IM, Harris DL, Glock RD, Matthews PJ \& Alexander TJL (1979) Pathogenic synergism between Treponema hyodysenteriae and other selected anaerobes in gnotobiotic pigs. Infection and Immunity 26, 1042-1047.

Windisch W, Schwartz FJ, Gruber K \& Kirchgessner M (1998) Effect of pharmacological dietary doses of zinc oxide on performance and fecal characteristics of weanling piglets. Agribiological Research - Zeitschrift für Agrarbiologie Agrikulturchemie Okologie 51, 277-285.

Wondra KJ, Hancock JD, Behnke KC, Hines RH \& Stark CR (1995a) Effects of particle size and pelleting on growth performance, nutrient digestibility, and stomach morphology in finishing pigs. Journal of Animal Science $\mathbf{7 3}$ 757-763.

Wondra KJ, Hancock JD, Behnke KC \& Stark CR (1995b) Effects of mill type and particle size uniformity on growth performance, nutrient digestibility, and stomach morphology in finishing pigs. Journal of Animal Science $\mathbf{7 3}$, $2564-2573$.

Wyatt GM, Horn N, Gee JM \& Johnson IT (1988) Intestinal microflora and gastrointestinal adaptation in the rat in response to non-digestible dietary polysaccharides. British Journal of Nutrition 60, 197-207.

Zhang P, Duhamel GE, Mysore JV, Carlson MPP \& Schneider NR (1995) Prophylactic effect of dietary zinc in a laboratory mouse model of swine dysentery. American Journal of Veterinary Research 56, 334-339.

Zhou W, Kornegay ET, Lindemann ML, Swinkels JWGM, Welten MK \& Wong EA (1994) Stimulation of growth by intravenous injection of copper in weanling pigs. Journal of Animal Science 72, 2395-2403. 
Proceedings of The Nutrition Society

\section{Editor:}

G R Goldberg London, UK

To order your subscription or for more information contact:

CABI Publishing,

$C A B$ International,

Wallingford,

Oxon, OX10 8DE, UK

Tel: + 44 (0)1491832111

Fax: + 44 (0)1491 829292

Email: publishing@cabi.org

CABI Publishing,

$\mathrm{CAB}$ International,

10 East 40th Street,

Suite 3203,

New York, NY 10016, USA

Tel: 2124817018

Toll free: 8005284841

Fax: 2126867993

Email: cabi-nao@cabi.org

\section{(1) $\mathrm{CABI} P$ ublishing}

Publishes the Proceedings of The Nutrition Society on behalf of The Nutrition Society

\section{Available on the Internet at}

www.cabi-publishing.org/journals

Throughout each year, The Nutrition Society holds important meetings and symposia, often in collaboration with other national and international learned societies, on topical and cutting edge aspects of nutrition science. All nutrition topics are covered, and the abstracts of original communications, and full papers by invited experts, are published in PNS.

Recent and forthcoming issues of PNS include symposia papers on:

- Nutritional adaptation to pregnancy and lactation

- Nutritional aspects of food safety

- Beyond the balanced diet

- Manipulating early diet

- Micronutrient supplementation - is there a case?

- Achieving a balanced diet in the developing world; strategies to meet micronutrient needs

- Evolving attitudes to food and nutrition

- Dietary fat - how low should we go ?

- Endocrine and nutritional modulation of the metabolic response to stress

- Nutrition in the post-genomic era

- Perspectives in the regulation of food intake

- Influence of social and cultural events on diet

- The food chain; plants, animals, man

- Energy metabolism and obesity

All this key information can be at your fingertips during 2002 by subscribing to the Proceedings of The Nutrition Society.

Six issues per year

ISSN: 0029-6651

2003, Volume 62

The 10th most cited journal in the nutrition and dietetics category, ISI Science Citation Index, 2000. Impact Factor: 2.33

$\begin{array}{lll}\text { Print only } & \text { Internet only } & \begin{array}{l}\text { Print/Internet } \\ \text { Package }\end{array} \\ € 305.00 & £ 295.00 & £ 320.00 \\ \$ 535.00 \text { Americas only } & \$ 515.00 \text { Americas only } \$ 560.00 \text { Americas only } \\ € 490.00 \text { EU only } & € 470.00 \text { EU only } & € 510.00 \text { EU only }\end{array}$

